Western University

Scholarship@Western

Chemistry Publications

Chemistry Department

9-15-2014

Resin-supported arylstannanes as precursors for radiolabeling with iodine: benzaldehydes, benzoic acids, benzamides, and NHS esters

Mustafa Janabi

Alumni, mjanabi@hotmail.com

Catherine M. Pollock

Alumni

Ann-Marie Chacko

Alumni,gmsac@nus.edu.sg

Duncan H. Hunter

UWO,dhunter@uwo.ca

Follow this and additional works at: https://ir.lib.uwo.ca/chempub

Part of the Polymer Chemistry Commons, and the Radiochemistry Commons

Citation of this paper:

Janabi, Mustafa; Pollock, Catherine M.; Chacko, Ann-Marie; and Hunter, Duncan H., "Resin-supported arylstannanes as precursors for radiolabeling with iodine: benzaldehydes, benzoic acids, benzamides, and NHS esters" (2014). Chemistry Publications. 30.

https://ir.lib.uwo.ca/chempub/30 
Can J Chem. Author manuscript;

Published in final edited form as:

$\square$ J Can. J. Chem. 2015, 93(2): 207-217.

Published online 2014 September 15. doi: 10.1139/cjc-2014-0265.

\title{
Resin-supported arylstannanes as precursors for radiolabeling with iodine: benzaldehydes, benzoic acids, benzamides and NHS esters
}

\author{
Mustafa Janabi, ${ }^{1,2}$ Catherine M. Pollock, ${ }^{1}$ Ann-Marie Chacko, ${ }^{1,3}$ and Duncan H. Hunter ${ }^{1}$ \\ ${ }^{1}$ The Department of Chemistry \\ The University of Western Ontario \\ London, ON, N6A 5B7 \\ ${ }^{2}$ Radiotracer Development \& \\ Imaging Technology Department \\ Lawrence Berkeley National Lab. \\ 1 Cyclotron Road, MS 55RO121 \\ Berkeley, CA, 94720 \\ ${ }^{3}$ Clinical Molecular Imaging \& Nuclear Medicine \\ Department of Radiology \\ Institute for Translation Medicine and Therapeutics \\ Perelman School of Medicine \\ University of Pennsylvania \\ Room 289, Chemistry Building 1958 Wing \\ 231 S. 34 Street Philadelphia, PA 19104 \\ Corresponding author: \\ Mustafa Janabi \\ Tel: 510-486-6361 \\ Fax: 510-486-4768 \\ E-mail: mjanabi@lbl.gov
}




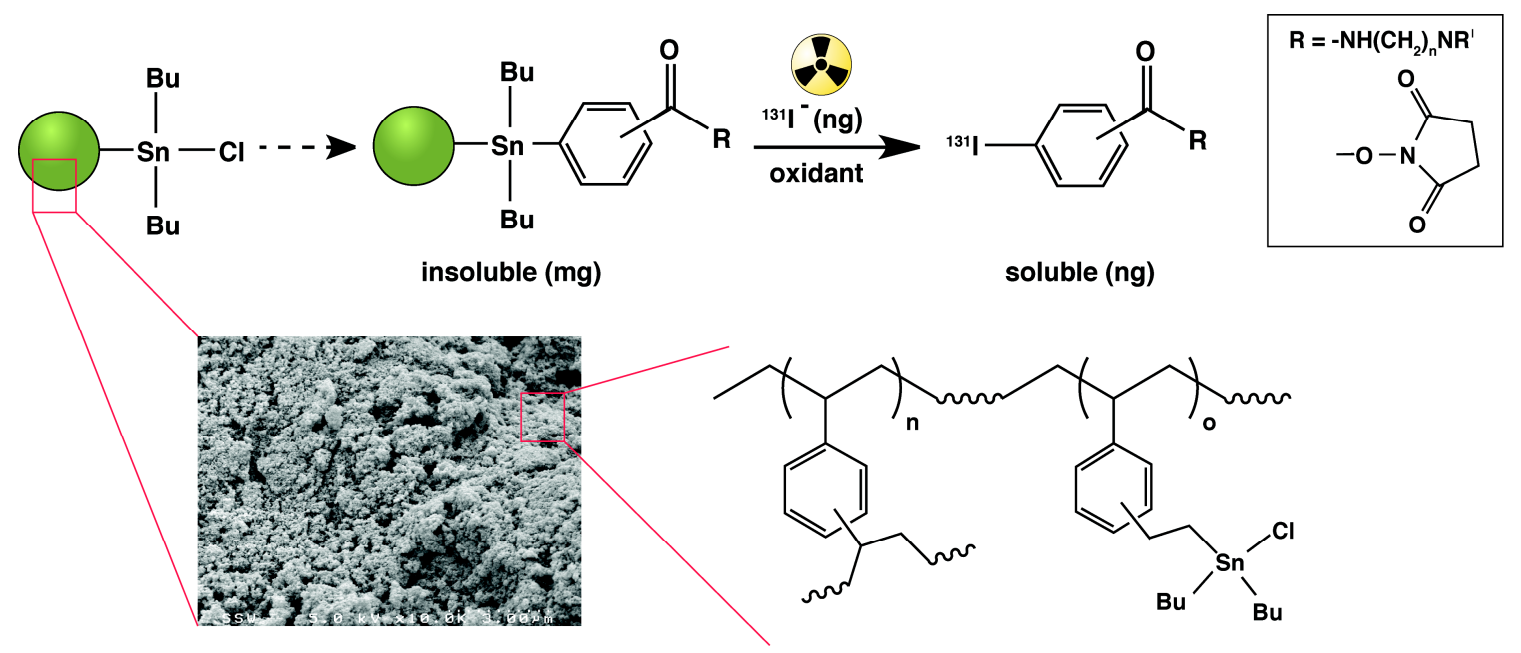

\begin{abstract}
A highly cross-linked polystyrene resin bearing a reactive chlorostannane moiety $\mathbf{1}$ has been used to generate a variety of arylstannane radiopharmaceutical precursors for no-carrieradded radioiodination. The resins were characterized for their solvent compatibility and sensitivity to acid cleavage. Resin-supported arylstannanes synthesized via their aryllithium analogues include 3- and 4-stannylbenzaldehydes, 3- and 4-stannylbenzoic acids, and 3- and 4$\mathrm{N}$-succinimidyl benzoates. A three-step route to the resin-supported stannylbenzoic acids $\mathbf{1 2} \mathbf{a} / \mathbf{b}$ was developed through resin-supported benzaldehydes $11 \mathbf{a} / \mathbf{b}$. The aldehyde to acid conversion efficiency is $>90 \%$, and acid loading capacities of $0.66-0.94 \mathrm{mmol} / \mathrm{g}$ were obtained. Resinsupported $N$-succinimidyl benzoates $\mathbf{1 6} \mathbf{a} / \mathbf{b}$ were prepared from the acid with $78-84 \%$ conversion efficiency. Libraries of resin-supported benzamides $19 \mathbf{a} / \mathbf{b}$ prepared from amine conjugation to corresponding benzoic acids or $N$-succinimidyl benzoates are described. A third approach describes the preparation of resin-supported benzamides via direct conjugation of the dilithio salt of the intact benzamide to the chlorostannane resin 1. Lastly, as proof-of-principle, a radiolabeling study with iodine-131 $\left({ }^{131} \mathrm{I}\right)$ was performed with a resin-supported benzamide to afford the corresponding radioligand in moderate yields, and high radiochemical purity.
\end{abstract}

Key Words: Solid phase organic chemistry (SPOC), radiopharmaceuticals, iodobenzamides, $N$ succinimidyl benzoate, radioiodination. 


\section{Introduction}

We have been investigating the applicability of insoluble resin-supported arylstannanes as precursors to radioiodinated pharmaceuticals with potential for diagnosis and therapy. ${ }^{1-6}$ The selected polystyrene (PS) resin-supported tin compound is not commercially available but its preparation had been previously reported along with numerous applications. ${ }^{7}$ This resin has been further adapted for the preparation of radioiodinated pharmaceuticals by preparing a resinsupported chlorostannane $\mathbf{1}$ (Fig. 1) as the precursor to arylstannanes of specific biological activity. As illustrated in Figure 1, the resin of interest is a copolymer of divinylbenzenes and 3\{dibutyl[2-(3-and 4-vinylphenyl)ethyl]stannyl chloride\}, itself prepared from the divinylbenzenes by mono-hydrochlorostannylation with dibutylchlorostannane. ${ }^{8}$

\section{[FIGURE 1]}

Two routes to resin-supported arylstannane precursors were envisioned, each involving aryllithium reagents (Fig. 2); one being the direct attachment of aryl-containing ligands of interest (Route A) and the second involving intermediate arylstannanes (Route B). Both approaches are reported here. One advantage of solid phase organic chemistry is the ability to drive reactions to completion by using excess reagents. Analogously, the resin-supported precursor is present in excess $(\mathrm{mg})$ during radiolabeling since the radioisotope is typically the limiting (ng) reagent. Hence, advantageously, the consumption of the typically expensive radioisotope can be driven to completion (Fig. 2). A further advantage of resin-based precursor radiolabeling is the rapidity in separating resin-bound tin materials, either the tin precursor or insoluble reaction by-product(s), by simple filtration of the resin to afford chemically pure radiolabeled compound in solution.

Tin-aryl bonds are susceptible to cleavage by many electrophilic reagents, including acids, halogens, $\mathrm{B}_{2} \mathrm{H}_{6} / \mathrm{H}_{2} \mathrm{O}_{2}$, and NOCl. ${ }^{9-10}$ While this places limitations on the chemistry that can be performed on the resin-supported arylstannanes without loss of the aryl group, it also creates advantages at the time of detachment. Beyond the use of electrophilic radioiodine, acids represent an interesting case where replacement of tin by hydrogen, results in a traceless linker. ${ }^{11}$

\section{[FIGURE 2]}

Both direct and indirect approaches to preparing resin-bound radiopharmaceutical precursors, typically through a PS system, have been described previously by our group and 
others. Direct attachment of the appropriate aryl lithium intermediate to resin $\mathbf{1}$ afforded the resin-bound precursor for $\left[{ }^{131} \mathrm{I}\right]-\mathrm{N}$-isopropyl-4-iodoamphetamine ([ $\left.{ }^{[31} \mathrm{I}\right]$-IMP), a SPECT imaging agent for monitoring brain perfusion. ${ }^{1}$ Treatment of this resin with radioiodine produced $\left[{ }^{131} \mathrm{I}\right]-$ IMP in 44\% radiochemical yield (RCY). Meta-iodobenzylguanidine (MIBG) is another compound that can be produced by a resin-bound precursor method. A four-step indirect approach was used to make the resin-supported 3-stannylbenzylguanidinium, beginning with lithiation of protected 3-bromobenzylamine and coupling with resin $1 .^{2-5}$ Radiolabeling with this resin has been scaled-up to the curie level as the route to no-carrier-added Azedra ([ $\left.{ }^{131} \mathrm{I}\right]$ $\mathrm{MIBG}),{ }^{12}$ and is currently in multi-center phase $2 \mathrm{~b}$ clinical trials as a radiotherapeutic for malignant pheochromocytoma, a rare adrenal tumor, and pediatric neuroblastoma, the most prevalent cancer in children. ${ }^{13-14}$ This specific resin has been further exploited as a convenient precursor to $\left[{ }^{211} \mathrm{At}\right]$-meta-astatobenzylguanidine $\left(\left[{ }^{211} \mathrm{At}\right]-\mathrm{MABG}\right),{ }^{15}$ used in alpha-particle emitting therapy of micrometastatic neuroendocrine tumors. A multi-step resin approach has also been applied to the ${ }^{123}$ I-radioiodination of Congo Red in $>56 \% \mathrm{RCY}$ and $>99 \%$ radiochemical purity (RCP), as an azo dye that localizes to forms of $\beta$-amyloid. ${ }^{16}$

PS resin-bound alkenyl stannyl precursors comprised of an alkenyl-tin bond have also been used for preparing a broad range of biologically active radiopharmaceuticals by radioiododestannylation. ${ }^{17-20}$ Examples of ${ }^{125}$ I-labeled vinyl iodides prepared by the resin-route include $(E)-1-\left[{ }^{125} \mathrm{I}\right]$-iododecene used en route to synthetic fatty acids and the acetate-protected analogue of $(E)-17 \alpha-\left[{ }^{125} I\right]$ iodovinylestradiol for targeting the estrogen receptor. ${ }^{21}$ These compounds were obtained in $20-70 \% \mathrm{RCY} .{ }^{21}$ Recently, a resin-bound stannylpropenyl mesylate was reported as a prosthetic group for attachment to diverse amines, and can be extended to alcohols, thiols, and peptide-based drug structures. ${ }^{22}$

A solid-phase strategy to macromolecular radiopharmaceuticals has also been described using a hydrophilic PEG-based resin. ${ }^{23}$ In particular, the preparation of the small molecule bioconjugate $N$-succinimidyl-3-[ $\left.{ }^{125} \mathrm{I}\right]$ iodobenzoate $\left(\left[{ }^{125} \mathrm{I}\right] \mathrm{SIB}\right)$ from a PEG resin-supported precursor was used to radiolabel a tomato plant systemin peptide and two proteins, globular albumin and $\operatorname{IgG}$ antibody. Analogous methods to radiopharmaceutical preparation include the use of soluble fluorine-rich supports that combines the advantage of purification and characterization of fluorous-tagged intermediate compounds. Most of the work to date has used fluorous arylstannanes as precursors to radioactive aryl iodides. ${ }^{24-26}$ A hybrid fluorous solid- 
phase radioiodination platform has similarly been used to provide "carrier-free" solutions of radiolabeled agents, including $\left[{ }^{125} \mathrm{I}\right]-\mathrm{MIBG} .{ }^{27}$ In recent years, a PS-resin based organotrifluoroborates has been synthesized towards preparing radioiodinated ligands. ${ }^{28-30}$

Described herein is the synthesis, physical, and chemical characteristics of resinsupported arylstannanes as precursors for radiolabeling with radioiodine. In particular, we describe resin-supported benzaldehydes, benzoic acids, $N$-succinimidyl benzoates, and benzamides. Benzaldehydes, benzoic acids, and $N$-succinimidyl esters are versatile functional moieties that can be used as radiolabeled bioconjugates, particularly for amine-bearing radiopharmaceuticals, such as amino acids, peptides, and proteins. Benzaldehyde resins also participate in condensation reactions with Schiff bases and aldols for the library synthesis of functionalized heterocycles via $\alpha, \beta$-unsaturated ketones. ${ }^{31}$

Halogenated benzamides themselves are of interest as nuclear imaging agents. ${ }^{32-33}$ In particular, structural analogues of $N, N$-dialkylamino-alkyl iodobenzamides with positional isomers of the halide, with different mono- and di-substituted $\mathrm{N}$-alkyl groups, and varying number of methylene bridge groups, have ranges of selectivity towards biological targets that are considered imaging biomarkers in cancer. ${ }^{34-40}$ Resin-supported 3- and 4-arylstannyl intermediates provide an opportunity to produce diverse libraries of radioiodobenzamide precursors to systematically assess structure activity relationships of various biological targets.

\section{Results and Discussion}

\section{Synthesis and characterization of resins}

\section{Composition}

Resin 1 used in this study was a copolymer prepared from commercial 20 mol-\% 3- and 4-divinylbenzenes (DVB) and 80 mol-\% 3-\{dibutyl[2-(3-and 4-vinylphenyl)ethyl]stannyl chloride\}, with the latter prepared by mono-hydrochlorostannylation of DVB with dibutylchlorostananne. ${ }^{8}$ The resin produced from emulsion polymerization and rapid stirring was an insoluble powder $10-300 \mu \mathrm{m}$ in diameter, with a porous surface as revealed by scanning electron microscopy (SEM, see supplemental data, Fig. S1). This material was chemically characterized by a combination of solid phase magic angle spinning (MAS) ${ }^{119}$ Sn NMR and 
diffuse reflectance infrared Fourier transform (DRIFT) IR spectroscopies, and by quantification of chemically released tin-bound species by hydrolysis or iodinolysis reactions.

Treatment of resin 1 with ethanolic $\mathrm{NaOH}$ at room temperature (RT) released free chloride ions, which upon titration revealed a $\mathrm{Sn}-\mathrm{Cl}$ resin loading capacity of $1.7 \mathrm{mmol} / \mathrm{g}$, as shown in Figure 3. The ${ }^{119}$ Sn NMR spectra before hydrolysis showed a single peak at $140-150$ ppm, reflective of a stannyl chloride group. This peak was replaced by two overlapping peaks at 91 and $101 \mathrm{ppm}$ after hydrolysis attributed to a combination of stannol 2 and stannoxane $\mathbf{3}^{8}$ Refluxing the hydrolyzed resin in $6 \mathrm{~mol} / \mathrm{L} \mathrm{HCl}$ regenerated resin $\mathbf{1}$, as confirmed by ${ }^{119} \mathrm{Sn} \mathrm{NMR}$.

[FIGURE 3]

The amount of chloride released was used to calculate the proportions of the two monomers incorporated into the resin, assuming all chloride released on hydrolysis came from the chlorostannane monomer. A loading capacity of $1.7 \mathrm{mmol}$ chloride/g of resin 1 translated into a resin comprised about 60\% DVB and 40\% 3-\{dibutyl[2-(3-and 4vinylphenyl)ethyl]stannyl chloride. This stood in stark contrast to the 20:80 proportion of monomers used to prepare the co-polymer. We do not have a satisfactory interpretation of this change.

\section{Solvent compatibility}

Resin 1 was prepared with a very high degree of crosslinking agent (20\%), compared with a $1-2 \%$ cross-linking agent used to produce most commercially available PS resins. Despite high cross-linking, resin 1 could repeatedly rapidly incorporate and dispel a variety of solvents. Solvent incorporation was monitored both by observing the increase in the apparent volume of the resin when wetted and by following the increase in weight and its subsequent decrease upon air filtering. Table 1 shows the ratio of the weight of solvent incorporated to the weight of resin and the volume ratio. Both ratios were a factor of 1-3 in several solvents, with the weight ratio being somewhat larger. The incorporation occurred almost immediately upon wetting. The volume ratio was determined visually, while the weight ratio was measured by following the decrease in weight when the wetted resin was exposed to the atmosphere. Except for DMSO, the solvent was rapidly lost depending on its volatility $(\leq 30 \mathrm{~min})$ and the resin returned to its original weight. Resin 1 would not wet with water alone. 
Resin 1 was converted to a 3-stannyl benzylammonium resin 4 (Fig. 4) en route to the MIBG resin, as described elsewhere. ${ }^{2}$ The presence of the ammonium groups made the resin more water compatible, as evidenced by the increase in the weight ratio relative to resin $\mathbf{1}$ (Table 1 , second column), allowing for the investigation of aqueous-based reactions. Concurrently, resin 4 was less hydrocarbon compatible, as the last two columns of Table 1 indicate.

[TABLE 1]

\section{Protodestannylation}

Resin 4 was used to monitor the stability of the tin-aryl carbon bonds under acidic conditions in order to determine which acid catalyzed transformations can be carried out without concomitant loss of aryl groups. The initial loading capacity for resin $\mathbf{4}$ was determined by $\mathrm{I}_{2}$ mediated iodinolysis, releasing 3-iodobenzylammonium 5 (Fig. 4). The filtrate following resin separation was subsequently analyzed by HPLC for quantification of $\mathbf{5}$ and indicated a loading of $1.30 \mathrm{mmol} / \mathrm{g}$ of resin. The progress of the protodestannylation reaction was similarly followed by HPLC to measure the amount of benzylammonium 6 released.

[FIGURE 4]

Various protodestannylation conditions were chosen to determine effects on the reaction rate. Treatment of resin 4 with $0.4 \mathrm{~mol} / \mathrm{L} \mathrm{HCl}$ in EtOH/ $\mathrm{H}_{2} \mathrm{O}$ at $\mathrm{RT}$ revealed slow release of 6 (Supplementary data, Fig. S2). Yields plateaued at $0.55 \mathrm{mmol} / \mathrm{g}$, which is only $43 \%$ of the maximum loading of resin 4 . Similar results were obtained using other strong acids (e.g., TFA and $\mathrm{H}_{2} \mathrm{SO}_{4}$ ) in a mixture of aqueous and non-aqueous solvents suggesting that the rate of protodestannylation is not dependent on the anion present. Weaker acids, like $\mathrm{HF}$ and $\mathrm{AcOH}$, were unable to release 6 under these conditions. In contrast, 1\% TFA in dichloromethane (DCM) $(0.4 \mathrm{~mol} / \mathrm{L})$ released $1.26 \mathrm{mmol} / \mathrm{g}$ of 6 within $15 \mathrm{~min}$ at RT. Refluxing resin 4 for $11.5 \mathrm{~h}$ in 0.4 $\mathrm{mol} / \mathrm{L} \mathrm{HCl}$ in EtOH$/ \mathrm{H}_{2} \mathrm{O}$, afforded a similar result, releasing $1.21 \mathrm{mmol} / \mathrm{g}$ of $\mathbf{6}$.

These results established the parameters for using mild acid catalysis with the resin, since $1 \mathrm{~h} \mathrm{HCl}$ treatment released $\leq 5 \%$ of the maximum loading of resin 4 (i.e. $0.05 \mathrm{mmol} / \mathrm{g}$ of $\mathbf{6}$ ). On the other hand, protodestannylation can be driven to completion by refluxing in $\mathrm{HCl} / \mathrm{EtOH} / \mathrm{H}_{2} \mathrm{O}$ or almost immediately with TFA/DCM at RT in non-ionizing solvent. The plateau in the slow release of 6 under mild $\mathrm{EtOH} / \mathrm{H}_{2} \mathrm{O}$ conditions suggests that about $40 \%$ of the benzylammonium 
groups are more readily available for reaction than the remaining tin-aryl groups. However, all benzylammonium groups will react under more forcing conditions.

\section{Synthesis and characterization of resin-supported radiopharmaceutical precursors}

\section{Resin-supported 3- and 4-stannyl benzoic acids $12 a$ and $12 b$ (direct versus indirect approach)}

Arylzinc benzoate derivatives have been used for coupling to $\mathrm{Sn}-\mathrm{Cl}$ containing fluorous soluble supports and have an advantage given the wide functional group tolerance of arylzinc species in cross-coupling reactions. ${ }^{24,26}$ Similarly, the solution-phase analogue of resin $\mathbf{1}$, tributylchlorostannane, reacts with the dilithio salt of bromobenzoic acids for arylstannylation. ${ }^{41}$ Interestingly, the analogous approach using resin $\mathbf{1}$ as a direct route to resin-supported benzoic acids through lithiated salts of 3- or 4-bromobenzoic acid proved unsuccessful.

We decided to explore the versatility of the organolithium approach using protecting groups. Given the acid sensitivity of the tin-aryl bond, the choice of protecting groups was somewhat limited, thus an indirect approach for obtaining resin-bound benzoic acids was deemed necessary. Oxazolidine-protected benzaldehydes were chosen as an appropriate intermediate, whereby the aldehyde was first masked with pseudoephedrine and later removed with dilute $\mathrm{AcOH}^{42-43}$ Resin-supported 3- and 4-stannyl benzoic acids $\mathbf{1 2 \mathbf { a }}$ and $\mathbf{1 2 b}$ were obtained by this indirect route (Fig. 5, where "a" consistently labels the 3-substituted arylstannyl resins and "b" the 4-substituted arylstannyl derivatives).

[FIGURE 5]

(i) Resin-supported 3- and 4-stannyl oxazolidinylbenzenes, $10 \mathrm{a}$ and $\mathbf{1 0 b}$

Refluxing 3- or 4-bromobenzaldehyde (7a/b) with pseudoephedrine (8) in benzene produced the corresponding bromo-oxazolidines $(\mathbf{9 a} / \mathbf{b})$ in near quantitative yield (Fig. 6). Oxazolidine derivatives $\mathbf{9 a} / \mathbf{b}$ were then treated with $n$-BuLi to produce the aryl-lithium intermediate in situ. To these solutions was added resin 1 as the limiting reagent ( 0.5 equiv.) to ensure complete conversion of $\mathrm{Sn}-\mathrm{Cl}$ to $\mathrm{Sn}$-aryl.

Analysis of the resultant resins by solid phase MAS ${ }^{119} \mathrm{Sn}$ NMR showed one signal at 41.8 and $-42.1 \mathrm{ppm}$ for resins $\mathbf{1 0 a}$ and 10b, respectively (for examples of representative spectra see Supplemental data). The absence of a peak in the range 140-150 ppm indicated that all 
$\mathrm{Sn}-\mathrm{Cl}$ sites on the resin had reacted and were occupied by aryl groups. To obtain the solid phase MAS ${ }^{119} \mathrm{Sn}$ NMR spectra, resins were swollen in either $\mathrm{CHCl}_{3}$ or toluene. This had the effect of narrowing the resonance peaks, allowing two peaks within 3-4 pm to be clearly identified. In addition to the normal $\mathrm{C}-\mathrm{H}$ and aromatic absorptions from the resin's backbone, solid phase IR spectra of these resins showed the presence of a C-O stretch at 1044 and $1048 \mathrm{~cm}^{-1}$ for resins 10a and 10b, respectively, consistent with the presence of the oxazolidine.

Iodinolysis proved to be an unreliable method of analysis for resin-supported 10a and 10b. The oxazolidine ring was unstable under iodinolysis conditions with the parent oxazolidine accounting for $<10 \%$ of the total area under the curve in HPLC. Consequently, loadings of resins $\mathbf{1 0 a} / \mathbf{b}$ were not determined.

\section{(ii) Resin-supported 3- and 4-stannyl benzaldehydes, $11 \mathrm{a}$ and $11 \mathrm{~b}$}

Resins 10a/b, treated with a mixture of $\mathrm{AcOH}, \mathrm{MeOH}$ and $\mathrm{H}_{2} \mathrm{O}(5: 5: 1)$ at RT for $24 \mathrm{~h}$, afforded resin-bound benzaldehydes $\mathbf{1 1 a} / \mathbf{b}$ and were subsequently analysed by the three methods

mentioned above. The ${ }^{119} \mathrm{Sn}$ NMR spectrum of the 4-stannylbenzaldehyde resin $\mathbf{1 1 b}$ showed one signal at $-39.8 \mathrm{ppm}$. This change in chemical shift from -42.1 to $-39.8 \mathrm{ppm}$, although small, was seen consistently. The IR spectrum showed characteristic aldehyde absorptions in addition to the usual polymer backbone signals. Additionally, the $\mathrm{C}-\mathrm{O}$ absorption stretch of the oxazolidine at $1048 \mathrm{~cm}^{-1}$ had disappeared. The IR spectrum confirmed the oxazolidine to aldehyde conversion but could not be used to quantify the extent of conversion. Iodinolysis and subsequent HPLC analysis of 4-iodobenzaldehyde $13 \mathrm{~b}$ released indicated a loading capacity of $0.78 \mathrm{mmol} / \mathrm{g}$ for resin 11b. Similarly, HPLC analysis of resin 11a showed $1.05 \mathrm{mmol}$ of 3-iodobenzaldehyde 13a per gram of resin. ${ }^{119} \mathrm{Sn}$ NMR and IR spectra showed results similar to that of resin $\mathbf{1 1 b}$.

Given that the oxazolidine hydrolysis conditions could promote protonolysis, the stability of the tin-aryl bond was confirmed by treating resin $\mathbf{1 1 b}$ for an additional $25 \mathrm{~h}$ at RT. HPLC analysis post iodinolysis indicated that resin $\mathbf{1 1 b}$ loading remained steady at $0.78 \mathrm{mmol} / \mathrm{g}$.

\section{(iii) Resin-supported 3- and 4-stannyl benzoic acids, $12 \mathrm{a}$ and $\mathbf{1 2 b}$}

The susceptibility of the Sn-aryl bond to acid protonolysis limited the choice of oxidizing agents for the conversion of the aldehyde to the acid. Hence, the focus was on agents such as the peroxyacids (i.e., peracetic acid, 3-chloroperbenzoic acid (mCPBA)) and the 
peroxides (i.e., benzoyl peroxide and oxone). With resin $\mathbf{1 1 b}$, peroxides gave incomplete conversion to acid, as evidenced by iodinolysis product mixtures of $\mathbf{1 3 b}$ and 4-iodobenzoic acid

14b. Interestingly, the ${ }^{119} \mathrm{Sn}$ NMR chemical shifts seemed somewhat sensitive to the substituents on the aromatic ring. In the case of the 3-substituents on resin 11a, the carbaldehyde and carboxyl groups showed ${ }^{119} \mathrm{Sn}$ chemical shifts at -39.2 and $-41.3 \mathrm{ppm}$, respectively. In cases where there were similar amounts of the aldehyde and acid, two overlapping closely spaced peaks could be observed (Supplementary data, Fig. S7). This difference in shifts was not apparent for the 4-substituted resins.

The most efficient conversions with resin 11a were achieved with five-fold excess of unpurified mCPBA, resulting in a mixture of $\sim 98 \%$ acid 14a and $\sim 2 \%$ aldehyde 13a following iodinolysis and HPLC. Similar results were observed with resin 11b: 92-95\% acid 14b and 8-5\% aldehyde 13b. Unpurified mCPBA contained approximately 7\% 3-chlorobenzoic acid, and use of purified mCPBA reduced conversion to about 50\%. Loadings for resin 11a were 0.93 $\mathrm{mmol} / \mathrm{g}$ acid and $0.01 \mathrm{mmol} / \mathrm{g}$ aldehyde, and resin $\mathbf{1 1 b}$ were $0.69 \mathrm{mmol} / \mathrm{g}$ acid and $0.03 \mathrm{mmol} / \mathrm{g}$ aldehyde. IR spectra for the acids were consistent with conversion from an aldehyde as seen by the loss of the dual carbonyl absorptions (1700 and $\left.1646 \mathrm{~cm}^{-1}\right)$, and the appearance of two new carbonyl signals at 1718 and $1689 \mathrm{~cm}^{-1}$. The former is attributed to a hydrogen-bonded acid dimer implying that the carboxylic acid groups can be in close contact with each other.

\section{Resin-supported 3- and 4-stannyl benzamides (indirect approach)}

A number of coupling reactions were carried out with resin-bound acids $\mathbf{1 2 a} / \mathbf{b}$ in an effort to conjugate amines for the preparation of resin-supported benzamides $\mathbf{1 5 a} / \mathbf{b}$. As shown in Figure 6, this was examined by (i) amine-conjugation directly to the acid using a coupling reagent (e.g., DCC) and (ii) formation of an active ester (i.e., $N$-succinimidyl ester resins 16a/b) for subsequent amine-conjugation. Radio-iodinolysis of resin $16 \mathbf{a}$ releases $\mathbf{1 7 a}$, which provides a prosthetic group that has found use in the radiolabeling of diverse amines. While both routes are sources of radioiodobenzamides $(\mathbf{1 8 a} / \mathbf{b})$, the latter method is applicable to amines, amino acids, and proteins. The former method is restricted to protected amines.

[FIGURE 6]

\section{(i) Direct diamine coupling with resin-supported acids $12 a / b$}


As illustrated in Figure 7, this study focused on dialkylamino(ethyl or propyl)amines using either direct coupling or through the resin supported $N$-succinimidyl esters, $\mathbf{1 6 a} / \mathbf{b}$. Thus, treatment of $\mathbf{1 2 b}$, which had a loading capacity of $0.66 \mathrm{mmol}$ of 4-benzoic acid per gram of resin, with DCC and $N, N$-diethylethylenediamine gave a benzamide-bound resin (19b-2, Table 2). The ${ }^{119}$ Sn NMR spectrum showed one peak slightly shifted upfield from the acid. This was as expected since the structural changes are remote from the tin. The IR spectra were consistent with a benzamide structure. Iodinolysis and HPLC confirmed $0.40 \mathrm{mmol}$ of $2-(\mathrm{N}, \mathrm{N}$ diethylamino)ethyl-4-iodobenzamide and $0.10 \mathrm{mmol}$ of $\mathbf{1 4 b}$ being released per gram of resin. The presence of $\mathbf{1 4 b}$ indicated that amide formation had not gone to completion under these conditions, the acid to amide conversion was $60 \%$.

\section{[FIGURE 7]}

A small library of resin-bound dialkylaminoethyl benzamides $19 \mathrm{~b}$ from resin $\mathbf{1 2 b}$ was produced using the DCC amine-coupling method by substituting different diamines (Table 2). The ${ }^{119}$ Sn NMR spectra of the resin-bound benzamides were all similar, showing one signal between -39.8 and -41.2 ppm. IR spectra showed the appearance of amide carbonyl absorptions between 1637 and $1658 \mathrm{~cm}^{-1}$. The iodobenzamides released from the small library of resins $\mathbf{1 9 b}$ are putative ligands for $\sigma$-receptors based on structure-activity relationships, ${ }^{44}$ including $N$-(2diethylaminoethyl)-4-[ ${ }^{123}$ I] iodobenzamide ([ $\left.\left.{ }^{123} \mathrm{I}\right] \mathrm{I}-\mathrm{BZA}\right)$ from resin 19b-2, which has favourable $\sigma$-receptor binding and has been successfully used clinically to image malignant melanoma. ${ }^{34-35}$ Interestingly, binding affinity studies show that 5 of the iodobenzamides have affinities improved over I-BZA (data not shown). Additional studies are needed to determine if this enhancement in affinity extends to improved radiopharmaceutical behaviour in vivo.

[TABLE 2]

\section{(ii) Coupling using resin-supported $N$-succinimidyl ester intermediates $16 \mathbf{a} / \mathbf{b}$}

$N$-succinimidyl-radioiodobenzoates are well-established prosthetic groups for the labeling of amines, amino acids, and peptides. ${ }^{41,45-46}$ Traditionally, they are produced from the corresponding $N$-succinimidyl tributylstannylbenzoates, ${ }^{41}$ and this solution phase approach necessitates cumbersome HPLC purification to remove toxic organotin compounds from the labeled product. Resin-supported stannyl $N$-succinimidyl esters $(\mathbf{1 6} \mathbf{a} / \mathbf{b})$ circumvent these challenges. As shown in Figure 6, resins $\mathbf{1 6 a / b}$ can serve as a bioconjugate by two approaches, 
with the first being through amine coupling to resin-supported benzamides, or by first releasing the prosthetic group into solution and then conjugating to the amine-containing ligand of choice. Herein we demonstrate the former approach.

Resins $\mathbf{1 6 a} / \mathbf{b}$ were obtained by treating resins $\mathbf{1 2 a} / \mathbf{b}$ with EDC and $N$ hydroxysuccinimide (NHS). The ${ }^{119}$ Sn NMR spectra showed one signal for resins $\mathbf{1 6} \mathbf{a} / \mathbf{b}$ that wase only slightly shifted from that of the acid. IR spectra showed the presence of appropriate carbonyl absorptions from the NHS moiety. Iodinolysis and HPLC analysis of resins 16a and $16 \mathbf{b}$ revealed the presence of $0.69 \mathrm{mmol} / \mathrm{g}$ and $0.53 \mathrm{mmol} / \mathrm{g}$ of $N$-succinimidyl 3- and 4iodobenzoate, respectively.

Resin 16a was treated with three $N, N$-alkylpropylenediamines at RT for 24 h to obtain resin-supported benzamides 19a-1 through 19a-3, whereas resin 16b was similarly treated with $N, N$-diethylethylenediamine to afford resin 19b-2. These specific resins were prepared, since the corresponding iodobenzamides had the more promising binding affinities to $\sigma$-receptors (data not shown). As presented in Table 3, this small library of resin-supported benzamides were prepared with $>96 \%$ efficiency from resins $\mathbf{1 6 a} / \mathbf{b}$ and had variable benzamide loadings ranging from 0.43-0.75 mmol/g. These results show that the NHS ester intermediates are similarly efficient at producing resin-bound stannyl benzamides $\mathbf{1 9} \mathbf{a} / \mathbf{b}$ as through amine-DCC coupling to the acidbound resins $\mathbf{1 2 a} / \mathbf{b}$. Regardless of the route, final resin-bound benzamide preparations contained 20-40\% benzoic acid moieties.

\section{[TABLE 3]}

In comparison to the good conversions experienced in obtaining the resin-supported acids from the aldehydes, the lower conversions to the amides encouraged us to look in more detail at this process. When resin $\mathbf{1 2 b}$ was treated with an alternative coupling agent DIC with 1-HOBT in DCM without subsequent addition of amine, the resultant resin showed two carbonyl absorptions at 1705 and $1784 \mathrm{~cm}^{-1}$, consistent with the symmetric and asymmetric stretches for an anhydride. This suggested that rather than remaining as active esters, a significant number reacted with adjacent carboxylic acid groups to form anhydrides. The IR spectrum of the acid

itself had revealed a carbonyl band at $1718 \mathrm{~cm}^{-1}$, consistent with hydrogen bonded acid dimers in support of this conjecture.

Subsequent reaction of the resin-supported anhydride with amine would result in equimolar amounts of amide and recovered acid. In an attempt to bypass this problem, several 
reaction parameters were tested without any improvement in conversion efficiency of acid to amide: reaction time was varied from several hours to days, coupling reagents were changed, and the sequence of reagent addition was modified, and the resin was re-treated.

The apparent inevitability of obtaining amides contaminated with significant amounts of acid and relatively enhanced amounts of aldehyde suggests that this route is of limited interest for the production of individual radiolabeled benzamides. However, a fast and convenient purification process was developed using solid phase extraction (SPE) of post-release mixtures of compounds from resins $\mathbf{1 9 a} / \mathbf{b}$. Following this method, iodobenzamides were isolated in 10 min with chemical purity $>90 \%$ (see Supplementary data for further description).

A comparison of the resin approach and the traditional approach seems appropriate given the need for a separation step with the resin. The resin approach involves separating an acid, a base, and a neutral, which was accomplished using SPE. The traditional approach through a tri$n$-butylstannylated benzamide involves the separation of the reputedly toxic tin tri- $n$-butylated precursor from the desired radioiodinated benzamide. The precursor is used in large excess and both the precursor and product are lipophilic and typically provide a difficult separation and rely upon a final HPLC purification step.

\section{Resin-supported 3- and 4-stannyl benzamides (direct approach)}

Resin-supported 3- and 4-stannylbenzamides $\mathbf{1 9 a} / \mathbf{b}$, prepared from either resins $\mathbf{1 2 a} / \mathbf{b}$ or $\mathbf{1 6} \mathbf{a} / \mathbf{b}$, allowed production of small libraries of iodobenzamides. However, with incomplete conversions over the multistep synthesis, significant contaminants were observed. While an albeit fairly rapid and simple purification procedure was established to remove the iodobenzoic acid and iodobenzaldehyde contaminants, this would not be feasible in scaling up the commercial production of radiohalogenated benzamides. Consequently, a direct route from the conjugation of chlorostannane resin 1 with lithio derivatives of bromobenzamides was explored as a convergent approach to resin-supported benzamides $19 \mathbf{a} / \mathbf{b}$.

A concern arises about the two competitive pathways for the reaction of bromobenzamides with an organolithium reagent: bromine-lithium exchange (transmetallation)

and deprotonation. ${ }^{47-50}$ Addition of a concentrated solution of the alkyllithium reagent (i.e., 2.5 $\mathrm{mol} / \mathrm{L} n-\mathrm{BuLi}$ ) to bromobenzamide led to internal quenching of any aryllithiated intermediates, most likely due to $n$-BuLi being in aggregate form. ${ }^{48}$ This quenching phenomenon can be 
minimized and altogether avoided by using a dilute solution of the organolithium to guarantee it being in monomeric form, and by inverting the mode of addition. ${ }^{4-49}$

A modified procedure was consequently devised and optimized where bromobenzamide solution was "inversely" added to a dilute THF solution of 3 equiv. of monomeric alkyllithium (i.e., $0.03 \mathrm{~mol} / \mathrm{L} t$-BuLi) with rapid stirring at $-78^{\circ} \mathrm{C}$ (Fig. 8). Quenching studies with MeOD confirmed the formation of the dilithio salt of the bromobenzamide. Subsequently, 0.5 equiv. of resin 1 were added in slow portions. Four 4-bromobenzamides were treated in this manner, and the preparation of the resin-bound 4-stannyl benzamides was verified via iodinolysis followed by HPLC, ${ }^{119}$ Sn NMR, and IR spectroscopies.

\section{[FIGURE 8]}

Iodinolysis revealed benzamide loadings for respective resins as follows: 19b-9, 0.37 $\mathrm{mmol} / \mathrm{g} ; 19 \mathrm{~b}-10,0.25 \mathrm{mmol} / \mathrm{g} ; \mathbf{1 9 b - 1 1}, 0.17 \mathrm{mmol} / \mathrm{g}$; and 19b-12, $0.53 \mathrm{mmol} / \mathrm{g}$. In each case, the 4-iodobenzamide was the only product observed by HPLC. ${ }^{119}$ Sn NMR spectra showed a major signal around $-41 \mathrm{ppm}$, attributable to the $\mathrm{Sn}-$ aryl bond, and a smaller broader peak around -82 ppm, assigned to Sn-O. The IR spectra were consistent with the assigned benzamide structure.

The direct approach from conjugation of resin 1 to lithiated $\mathrm{N}$-alkylbromobenzamides gave yields comparable to the indirect approach through resins $\mathbf{1 2 a} / \mathbf{b}$, but the former has the advantage of producing material in high chemical purity. This would be of considerable value for production of radiopharmaceuticals with established biological potential, since additional purification steps require time, and result in concomitant loss of radioactivity.

\section{Radiolabeling with ${ }^{131}$ I}

Because carbamide groups are deactivators in electrophilic aromatic substitution reactions such as radioiodination, resin-supported benzamide 19b-7 was chosen to illustrate radiolabeling with ${ }^{131} \mathrm{I}$ (half-life $\left(\mathrm{t}_{1 / 2}\right)=8 \mathrm{~d}$ ) as proof-in-principle. No attempt was made to optimize the labeling yields of the resin-supported precursor 19b-7 to $N$-(2-morpholinylethyl)-4iodobenzamide (20b-7). The reaction mixture from the radioiodination of 19b-7 was also chosen to test the radioiodobenzamide purification process. Radiolabeling with $\sim 150 \mathrm{MBq}(4.05 \mathrm{mCi})$ of $\left[{ }^{131} \mathrm{I}\right] \mathrm{NaI}$ with peracetic acid as oxidant resulted in a mixture of radiolabeled compounds: $\left[{ }^{131} \mathrm{I}\right]-$ $N$-(2-morpholinylethyl)-4-iodobenzamide ( 50\% RCY); [ $\left.{ }^{131} \mathrm{I}\right]$-4-iodobenzaldehyde ( 10\% RCY); [ $\left.{ }^{131} \mathrm{I}\right]$-4-iodobenzoic acid ( 20\% RCY), as estimated by radioHPLC (Fig. 9). Following 
SPE purification, radioiodobenzamide was obtained with $>90 \%$ RCP and 37\% RCY. $\left[{ }^{131} \mathrm{I}\right]-4-$ iodobenzaldehyde remained around 10\%. With good isolated radiochemical purities and moderate radiochemical yields for initial radiolabeled studies, this encouraging result suggests room for optimization in using resin-supported arylstannanes towards radiolabeled precursors.

[FIGURE 9]

\section{Conclusions}

With an eye to providing effective precursors to iodine labeled radiopharmaceuticals, resin-supported arylstannanes have been synthesized to provide no-carrier-added radioiodide compounds free of toxic tin-bearing precursors and side-products that can be difficult to remove. Resins $\mathbf{1}$ and $\mathbf{4}$ were tested for their solvent compatibility and resin $\mathbf{4}$ for its acid sensitivity. Described are two library-based approaches and a final direct approach to creating single resinsupported pharmaceuticals of chemical high purity. Resin supported 3-and 4-stannyl benzaldehydes $(11 \mathbf{a} / \mathbf{b})$, benzoic acids $(\mathbf{1 2 a} / \mathbf{b})$ and $N$-succinimidyl benzoates $(16 \mathbf{a} / \mathbf{b})$ were prepared using aryllithium intermediates. In turn, these were converted to small libraries of benzamide precursors $(19 \mathbf{a} / \mathbf{b})$. The conversion of benzaldehydes to benzoic acids proceeded in high yield and provided iodobenzoic acids with good purity. The conversion of benzoic acids to benzamides was less successful and was interpreted to proceed to a significant extent through resin supported benzoic acid anhydrides. A third, more successful approach, involved the direct conjugation of the dilithio salt of an intact halobenzamide to the chlorostannane resin $\mathbf{1}$. This provided iodobenzamides in high purity. Resin 19b-7 was successfully radiolabeled with ${ }^{131} \mathrm{I}$. While radiolabeling yields were not optimized in this study, this points the way to using the approaches developed for solid phase organic chemistry for generating new radiopharmaceuticals by preparing and screening much larger libraries. 


\section{Experimental}

\section{Instruments and materials}

Chemicals and reagents were purchased from Sigma-Aldrich, Lancaster or Gelest and used without further purification unless otherwise indicated. THF and DCM solvents were freshly distilled from potassium-benzophenone and calcium hydride stills, respectively. $\mathrm{SiO}_{2}$ chromatography was used to remove stabilizers from commercial grade divinylbenzene (DVB) (with $\sim 20 \%$ ethylvinylbenzene).

${ }^{1} \mathrm{H}$ NMR and ${ }^{13} \mathrm{C}$ NMR spectra were obtained using either a Varian Gemini 300 (300 $\mathrm{MHz}$ for $\left.{ }^{1} \mathrm{H}\right)$ or a Varian Mercury $400\left(400 \mathrm{MHz}\right.$ for $\left.{ }^{1} \mathrm{H}\right)$ spectrometer. ${ }^{1} \mathrm{H}$ NMR spectra of 4disubstituted aromatics were analyzed as AB spectra. Solid phase MAS ${ }^{119} \mathrm{Sn}$ NMR spectra were obtained on a Varian Infinity Plus 400 spectrometer (400 MHz for ${ }^{1} \mathrm{H}$ ) using a Chemmagnetics $7.5 \mathrm{~mm}$ probe spinning at an angle of $54.74^{\circ}$. Spectra were obtained with acquisition at 120 $\mathrm{MHz}$, using a $45^{\circ}$ pulse with a $5 \mathrm{~s}$ delay between pulses. Resins were pre-treated with toluene or chloroform prior to obtaining ${ }^{119}$ Sn NMR spectra. A Bruker FT-IR with a Spectra-Tech diffuse reflectance attachment (DRIFT) was used for resin samples. The Kubelka-Munk conversion was used instead of an absorbance scale for the resin samples for improved signal to noise ratio. A Finnigan MAT 8230 Mass Spectrometer was used to obtain the mass spectra.

\section{Proto and iododestannylation procedures for resin 4 Using 1\% TFA in DCM}

To a $5 \mathrm{~mL}$ vial was added resin $4(50.3 \mathrm{mg}, 65.4 \mu \mathrm{mol})$, DCM $(1.98 \mathrm{~mL})$ and TFA (20 $\mu \mathrm{L}, 0.26 \mathrm{mmol}$ ). After shaking in a sealed vial for $15 \mathrm{~min}$ at $\mathrm{RT}$, the mixture was transferred into a $25 \mathrm{~mL}$ flask and the solvent was removed in vacuo. EtOH $(3 \mathrm{~mL})$ and a $0.2 \mathrm{~mol} / \mathrm{L} \mathrm{I}_{2}$ solution in EtOH $(40 \mu \mathrm{L}, 8 \mu \mathrm{mol})$ were added to the residue. After stirring for $3 \mathrm{~h}$ at RT, a $0.1 \mathrm{~mol} / \mathrm{L}$ sodium metabisulfite solution $(0.2 \mathrm{~mL}, 20 \mu \mathrm{mol})$ was added. This solution was adjusted to $\mathrm{pH}=5-6$ with $0.1 \mathrm{~mol} / \mathrm{L} \mathrm{NaOH}$ and diluted to $25 \mathrm{~mL}$ with $\mathrm{H}_{2} \mathrm{O}$. An aliquot was filtered through a syringe filter and then analysed by HPLC to determine the amount of $\mathbf{5}$ and $\mathbf{6}$ released. 


\section{Using $0.4 \mathrm{~mol} / \mathrm{L} \mathrm{HCl}$ in $\mathrm{EtOH} / \mathrm{H}_{2} \mathrm{O}, 1: 1.25$}

About $50 \mathrm{mg}$ of resin 4 was suspended in $0.4 \mathrm{~mol} / \mathrm{L} \mathrm{HCl}$ in an $\mathrm{EtOH} / \mathrm{H}_{2} \mathrm{O}$ mixture (1:1.25) and shaken for the selected time. The resin was removed by filtration, washed and the filtrate taken to dryness with a rotary evaporator. The residue was treated with $\mathrm{H}_{2} \mathrm{O}$ and adjusted to $\mathrm{pH}=5-6$ with $0.1 \mathrm{~mol} / \mathrm{L} \mathrm{NaOH}$. This solution was diluted to $10 \mathrm{~mL}$ and analyzed by HPLC against standard solutions.

\section{Solvent compatibility of resins 1 or 4}

Resin $\mathbf{1}$ or $\mathbf{4}$ was ground into a fine powder with a mortar and pestle. A NMR tube was filled with this powder to a height of about $10 \mathrm{~mm}$, then $1 \mathrm{~mL}$ of a selected solvent was added to the NMR tube. After stirring to ensure wetting of the powder, the suspension was allowed to settle for $24 \mathrm{~h}$ and the height of the resin column in the tube was re-measured. Solvent compatibility was calculated as [(volume of wet resin [minus] volume of dry resin)/volume of dry resin].

Alternatively, about $100 \mathrm{mg}$ of resin $\mathbf{1}$ or $\mathbf{4}$ in a 4 dram vial was soaked in an excess of the selected solvent for $24 \mathrm{~h}$. The suspension was transferred to a tared sintered glass funnel and vacuum filtered until the bulk of the solvent had been removed. The funnel and contents were then weighed. The decrease in weight was followed for a period of $2 \mathrm{~h}$ by which time the weight remained constant near the original weight for most solvents except DMSO. Solvent compatibility was calculated as [(weight of wet resin [minus] volume of dry resin)/volume of dry resin].

\section{General procedure for the iodinolysis of resins}

To a suspension of resin $(\sim 20 \mathrm{mg})$ in $\sim 2 \mathrm{~mL}$ acetonitrile $\left(\mathrm{CH}_{3} \mathrm{CN}\right), \sim 1 \mathrm{~mL}$ of $\mathrm{I}_{2} / \mathrm{CH}_{3} \mathrm{CN}$ $(0.1 \mathrm{~mol} / \mathrm{L})$ was added. After shaking at RT for $2 \mathrm{~h}$, an aqueous solution of sodium thiosulfate $(0.2 \mathrm{~mol} / \mathrm{L})$ was added until a colorless solution was obtained. Upon dilution to $25 \mathrm{~mL}$ with $\mathrm{MeOH}$, a portion of this suspension was filtered through a Whatman $0.45 \mu \mathrm{m}$ nylon syringe filter. These solutions were analyzed by HPLC against a standard solution of the appropriate authentic iodo-compound for both retention time and area (see Supplementary data for HPLC conditions and for synthesis of standards where appropriate). 
Preparation of (4S, 5S)-2-(3- and 4-Bromophenyl)-3, 4-dimethyl-5-phenyl-1, 3-oxazolidine (9a and 9b)

Into a one-necked $250 \mathrm{~mL}$ round-bottomed flask, equipped with a Dean-Stark trap and a condenser, was placed 3-bromobenzaldehyde (7a, $8.78 \mathrm{~g}, 47.5 \mathrm{mmol})$ and $(S, S)-(+)-$ pseudoephedrine $(\mathbf{8}, 7.83 \mathrm{~g}, 47.4 \mathrm{mmol})$, and benzene $(180 \mathrm{~mL})$. After $18 \mathrm{~h}$ reflux, benzene was removed under reduced pressure, to give a yellow oil which solidified upon standing. A white solid (m.p. $73-75^{\circ} \mathrm{C}$ ) was obtained after recrystallization from hexanes $(\mathbf{9 a}), 14.78 \mathrm{~g}(94 \%) .{ }^{1} \mathrm{H}$ NMR spectrum $\left(\mathrm{CDCl}_{3},\right) \delta: 7.75(\mathrm{~s}, 1 \mathrm{H}), 7.51-7.26(\mathrm{~m}, 8 \mathrm{H}), 4.93(\mathrm{~s}, 1 \mathrm{H}), 4.76\left(\mathrm{~d}, 1 \mathrm{H},{ }^{3} J_{\mathrm{H}-\mathrm{H}}=\right.$ $7.2 \mathrm{~Hz}), 2.56(\mathrm{~m}, 1 \mathrm{H}), 2.23(\mathrm{~s}, 3 \mathrm{H}), 1.23\left(\mathrm{~d}, 3 \mathrm{H},{ }^{3} \mathrm{~J}_{\mathrm{H}-\mathrm{H}}=5.6 \mathrm{~Hz}\right) .{ }^{13} \mathrm{C} \mathrm{NMR}$ spectrum $\left(\mathrm{CDCl}_{3},\right) \delta$ : 141.96, 139.91, 132.08, 130.95, 129.86, 128.37, 128.00, 126.76, 126.61, 122.50, 98.60, 86.60, 68.62, 35.12, 14.23. IR spectrum $\left(\mathrm{CH}_{2} \mathrm{Cl}_{2}, \mathrm{~cm}^{-1}\right): 2972$ and $2792(\mathrm{C}-\mathrm{H}), 1575$ and $1460(\mathrm{C}=\mathrm{C})$, 1043 (C-O). HRMS, m/z: calcd. for $\mathrm{C}_{16} \mathrm{H}_{18} \mathrm{NO}^{79} \mathrm{Br} 332.0650$, found 332.0644.

Analogously, 4-bromobenzaldehyde (7b, $500 \mathrm{mg}, 2.7 \mathrm{mmol}),(S, S)-(+)$-pseudoephedrine $(\mathbf{8}, 450 \mathrm{mg}, 2.7 \mathrm{mmol})$ and benzene $(40 \mathrm{~mL})$ were refluxed for $18 \mathrm{~h}$. Solvent evaporation yielded a clear, colorless, viscous oil (9b), $883 \mathrm{mg}(98 \%)$. ${ }^{1} \mathrm{H}$ NMR spectrum $\left(\mathrm{CDCl}_{3}\right) \delta: 7.42(\mathrm{~d}, 2 \mathrm{H}$, $\left.{ }^{3} J_{\mathrm{H}-\mathrm{H}}=8.4 \mathrm{~Hz}\right), 7.35-7.20(\mathrm{~m}, 7 \mathrm{H}), 4.82(\mathrm{~s}, 1 \mathrm{H}), 4.65\left(\mathrm{~d}, 1 \mathrm{H},{ }^{3} J_{\mathrm{H}-\mathrm{H}}=8.4 \mathrm{~Hz}\right), 2.45(\mathrm{~m}, 1 \mathrm{H}), 2.09$ $(\mathrm{s}, 3 \mathrm{H}), 1.12\left(\mathrm{~d}, 3 \mathrm{H},{ }^{3} J_{\mathrm{H}-\mathrm{H}}=6.0 \mathrm{~Hz}\right) .{ }^{13} \mathrm{C} \mathrm{NMR}$ spectrum $\left(\mathrm{CDCl}_{3}\right) \delta: 139.97,138.53,131.38$, $129.68,128.33,127.94,126.56,122.91,98.69,86.50,68.59,35.00,14.19$. IR spectrum $\left(\mathrm{CH}_{2} \mathrm{Cl}_{2}\right.$, $\mathrm{cm}^{-1}$ ): 2974 and $2793(\mathrm{C}-\mathrm{H}), 1594,1489$ and $1456(\mathrm{C}=\mathrm{C}), 1043$ (C-O). HRMS, m/z: calcd. for $\mathrm{C}_{16} \mathrm{H}_{18} \mathrm{NO}^{79} \mathrm{Br} 332.0650$, found 332.0647 .

\section{Poly-(4S, 5S)-2-(3- and 4-\{dibutyl[2-(3-and 4-vinylphenyl)ethyl]stannyl $\}$ phenyl)-3, 4- dimethyl-5-phenyl-1, 3-oxazolidine)-co-divinylbenzene (Resin 10a and 10b)}

To (4S, 5S)-2-(3-bromophenyl)-3,4-dimethyl-5-phenyl-1,3-oxazolidine (9a, 2.90 g, 8.7 mmol) in a three-necked flask equipped with a T-bore stopcock, a rubber septum and a powder addition side arm containing resin 1 (4.01 g, $5.9 \mathrm{mmol} \mathrm{Sn}-\mathrm{Cl})$ was added dry THF (30 mL) under Ar. To this solution was added $n$-BuLi $(3.0 \mathrm{~mL}, 7.5 \mathrm{mmol}, 2.5 \mathrm{~mol} / \mathrm{L})$ at $-78^{\circ} \mathrm{C}$. After $2 \mathrm{~h}$ at $-78^{\circ} \mathrm{C}$, resin 1 was tipped into the THF solution, the suspension was allowed to stir for about $18 \mathrm{~h}$ as it warmed to RT. $\mathrm{MeOH}(3 \mathrm{~mL})$ was added and the suspension was filtered and washed with $\mathrm{MeOH}, \mathrm{H}_{2} \mathrm{O}, \mathrm{MeOH} / \mathrm{H}_{2} \mathrm{O}$ /acetone, $\mathrm{MeOH} /$ acetone, and $\mathrm{MeOH}$ several times to yield $4.3 \mathrm{~g}$ 
of resin 10a after drying. MAS ${ }^{119} \mathrm{Sn}$ NMR spectrum (toluene): $-41.8 \mathrm{ppm}$. DRIFT-IR spectrum (solid, $\left.\mathrm{cm}^{-1}\right)$ : $1044(\mathrm{C}-\mathrm{O})$.

Similarly, (4S, 5S)-2-(4-bromophenyl)-3,4-dimethyl-5-phenyl-1,3-oxazolidine (9b, 1.02 g, $3.1 \mathrm{mmol})$ in dry THF $(35 \mathrm{~mL})$ was reacted with $n$-BuLi $(2.5 \mathrm{~mol} / \mathrm{L}, 1.2 \mathrm{~mL}, 3.0 \mathrm{mmol})$ and resin $1(1.05 \mathrm{~g}, \sim 1.6 \mathrm{mmol} \mathrm{Sn}-\mathrm{Cl})$ to yield $1.24 \mathrm{~g}$ of resin 10b. MAS ${ }^{119} \mathrm{Sn}$ NMR spectrum (toluene): -42.1 ppm. DRIFT-IR spectrum (solid, $\mathrm{cm}^{-1}$ ): $1048(\mathrm{C}-\mathrm{O})$.

\section{Poly-(3- and 4-\{dibutyl[2-(3-and-4-vinylphenyl)ethyl]stannyl\}benzaldehyde)-co- divinylbenzene (Resins 11a and 11b)}

Resin 10a (3.98 g) was treated with a mixture of $\mathrm{AcOH}(25 \mathrm{~mL}), \mathrm{MeOH}(25 \mathrm{~mL})$, and $\mathrm{H}_{2} \mathrm{O}(9 \mathrm{~mL})$ with gentle shaking at RT for $27 \mathrm{~h}$. The solid was recovered by filtration and was washed successively with $\mathrm{MeOH}, \mathrm{H}_{2} \mathrm{O}, \mathrm{MeOH} / \mathrm{H}_{2} \mathrm{O}$ /acetone, $\mathrm{MeOH} /$ acetone, and $\mathrm{MeOH}$ to yield $3.65 \mathrm{~g}$ of resin 11a. MAS ${ }^{119} \mathrm{Sn}$ NMR spectrum (toluene): -39.2 ppm. DRIFT-IR spectrum (solid, $\mathrm{cm}^{-1}$ ): 2716 (aldehyde $\mathrm{C}-\mathrm{H}$ stretch), 1699 (aldehyde $\mathrm{C}=\mathrm{O}$ ), 1645 (aldehyde $\mathrm{C}=\mathrm{O}$ ). Iodinolysis: $1.05 \mathrm{mmol}$ of 10a per gram of resin 11a.

Resin $10 b$ (1.22 g) was treated with a mixture of $\mathrm{MeOH}(5 \mathrm{~mL}), \mathrm{H}_{2} \mathrm{O}(1.5 \mathrm{~mL})$, and $\mathrm{AcOH}(5 \mathrm{~mL})$ with shaking at RT for $17 \mathrm{~h}$. The solid was filtered and washed to yield $1.00 \mathrm{~g}$ of resin 11b. MAS ${ }^{119} \mathrm{Sn}$ NMR spectrum (toluene): $-39.8 \mathrm{ppm}$. DRIFT-IR spectrum (solid, $\mathrm{cm}^{-1}$ ): $2715(\mathrm{CHO})$; $1707(\mathrm{C}=\mathrm{O})$. Iodinolysis: $0.78 \mathrm{mmol}$ of $\mathbf{1 0 b}$ per gram of resin $\mathbf{1 1 b}$.

\section{Poly-(3- and 4-\{dibutyl[2-(3-and-4-vinylphenyl)ethyl]stannyl\}benzoic acid)-co- divinylbenzene (Resins 12a and 12b)}

Resin 11a (103 mg, 0.087 mmol of aldehyde) was added to a vial and swollen with reagent grade $\mathrm{MeOH}(5 \mathrm{~mL})$. To the mixture was added mCPBA ( 93\%, $102 \mathrm{mg}, 0.20 \mathrm{mmol})$. After shaking for $24 \mathrm{~h}$ at RT, the solid was filtered and washed successively with $1 \mathrm{~mol} / \mathrm{L}$ $\mathrm{NaOH}$, acetone, $1.7 \mathrm{~mol} / \mathrm{L} \mathrm{AcOH} / \mathrm{EtOH}, \mathrm{H}_{2} \mathrm{O}, \mathrm{MeOH} / \mathrm{H}_{2} \mathrm{O} /$ acetone, and $\mathrm{MeOH}$ to afford $93 \mathrm{mg}$ of resin 12a. MAS ${ }^{119} \mathrm{Sn}$ NMR spectrum (toluene): -39.7 ppm. DRIFT-IR spectrum (solid, $\mathrm{cm}^{-1}$ ): 3700-2500 (O-H), $1718(\mathrm{C}=\mathrm{O}), 1689(\mathrm{C}=\mathrm{O})$. Iodinolysis: $0.93 \mathrm{mmol}$ of $\mathbf{1 4 a}$ and $0.01 \mathrm{mmol}$ of 13a per gram of resin 12a.

As per resin 11a, resin 11b $(210 \mathrm{mg}, \sim 0.15 \mathrm{mmol})$ was treated with mCPBA ( 90\%, 298 $\mathrm{mg}, 0.6 \mathrm{mmol})$ in $\mathrm{MeOH}(5 \mathrm{~mL})$ to yield $188 \mathrm{mg}$ of resin $\mathbf{1 2 b}$. MAS ${ }^{119} \mathrm{Sn}$ NMR spectrum 
$\left(\mathrm{CHCl}_{3}\right):-40.9$ ppm. DRIFT-IR spectrum (solid, $\left.\mathrm{cm}^{-1}\right): 3600-2500(\mathrm{O}-\mathrm{H}$, broad), 1725 and 1691 $(\mathrm{C}=\mathrm{O})$. Iodinolysis: $0.66 \mathrm{mmol}$ of $\mathbf{1 4 b}$ and $0.03 \mathrm{mmol}$ of $\mathbf{1 3 b}$ per gram of resin $\mathbf{1 2 b}$.

\section{Typical procedure for preparation of resin-supported stannyl-bound dialkyldiamines} (Resins 19a and 19b) from Resins 12a and 12b.

Poly-(4-\{dibutyl[2-(3-and 4-vinylphenyl)ethyl]stannyl\}-N,N-diethylethylene diaminobenzamidyl)-co-divinylbenzene (19b-2)

Into a $50 \mathrm{~mL}$ round-bottom flask were placed $N, N$-diethylethylenediamine $(28 \mathrm{mg}, 0.24$ mmol), collidine (27 mg, $0.22 \mathrm{mmol}$ ), DCC (61 mg, $0.30 \mathrm{mmol}$ ), 1-HOBT (32 mg, $0.21 \mathrm{mmol}$ ), resin $12 \mathbf{b}(150 \mathrm{mg}, \sim 0.10 \mathrm{mmol})$, and DCM ( $5 \mathrm{~mL})$. After stirring under an atmosphere of argon for 7 days at RT, the solid was filtered and washed with $\mathrm{MeOH} /$ acetone, $\mathrm{DCM}$, and $\mathrm{MeOH}$ solutions successively ( $3 \times 15 \mathrm{~mL}$ ), to yield $150 \mathrm{mg}$ of resin 19b-2. MAS ${ }^{119} \mathrm{Sn}$ NMR spectrum $\left(\mathrm{CHCl}_{3}\right)$ : -41.2 ppm. DRIFT-IR spectrum (solid, $\left.\mathrm{cm}^{-1}\right)$ : $1653(\mathrm{C}=\mathrm{O}), 3343(\mathrm{~N}-\mathrm{H})$. Iodinolysis: $0.40 \mathrm{mmol} N, N$-(2-diethylaminoethyl)-4-iodobenzamide 20b-2, $0.10 \mathrm{mmol}$ of $\mathbf{1 4 b}$ and 0.05 mmol of 13b per gram of resin.

The same procedure was utilized for the formation of the library of resin-bound stannyl benzamides $(19 \mathbf{a} / \mathbf{b})$ by substituting different diamines for $N, N$-diethylethylenediamine. MAS ${ }^{119} \mathrm{Sn}$ NMR spectra $\left(\mathrm{CHCl}_{3}\right)$ showed one peak in the range -39.8 to $-41.2 \mathrm{ppm}$. DRIFT-IR spectra (solid, $\mathrm{cm}^{-1}$ ) showed $\mathrm{C}=\mathrm{O}$ absorptions in the range 1637 to 1653 and $\mathrm{N}-\mathrm{H}$ around 3343 . Iodinolysis results are presented in Table 2.

\section{General procedure for the preparation of resin-supported 3- and 4-stannyl $N$-succinimidyl} benzoates (16a and 16b) from resin 12a and 12b.

Resin-supported benzoic acid (50 mg 12a or 12b) was swollen with DCM for $10 \mathrm{~min}$ and to this was added EDC (59 mg, $0.31 \mathrm{mmol}$ ), NHS (35 mg, $0.30 \mathrm{mmol}$ ), collidine ( $52 \mathrm{mg}, 0.43$ $\mathrm{mmol}$ ), and DCM (4 mL). The NHS solution was then added to the resin suspension followed by stirring at RT for $24 \mathrm{~h}$. The suspension was filtered and the resin was washed with DCM and acetone several times to yield the corresponding resin-bound active ester $\mathbf{1 6 a}$ or $\mathbf{1 6 \mathbf { b }}$.

16a: MAS ${ }^{119} \mathrm{Sn}$ NMR spectrum (toluene): $-38.5 \mathrm{ppm}$ (Sn-aryl). DRIFT-IR (solid, $\mathrm{cm}^{-1}$ ): 1772 $(\mathrm{C}=\mathrm{O}$ (asymmetric)), $1746(\mathrm{C}=\mathrm{O}$ (symmetric)), $1071(\mathrm{C}-\mathrm{N})$. Iodinolysis: $0.69 \mathrm{mmol}$ of $17 \mathbf{a}$ and $0.13 \mathrm{mmol}$ of 14a per gram of resin. 
16b: MAS ${ }^{119} \mathrm{Sn}$ NMR spectrum (toluene): -39.4 ppm (Sn-aryl). DRIFT-IR (solid, $\mathrm{cm}^{-1}$ ): 1773 $(\mathrm{C}=\mathrm{O}$ (asymmetric)), $1743(\mathrm{C}=\mathrm{O}$ (symmetric)). Iodinolysis: $0.53 \mathrm{mmol}$ of $\mathbf{1 7 b}$ and $0.06 \mathrm{mmol}$ of 14b per gram of resin.

\section{General procedure for the preparation of resin-supported 3- and 4-stannyl benzamides} (19a and 19b) from resin $16 a$ and $16 b$.

Resin-supported active ester (200 mg, 16a or 16b) was swollen with DCM (5 mL) for 10 min. To resin was added diamine and the reaction was allowed to stir for $24 \mathrm{~h}$ at RT. The solid was filtered and washed with $\mathrm{MeOH}$, acetone $/ \mathrm{H}_{2} \mathrm{O}, \mathrm{MeOH} / \mathrm{H}_{2} \mathrm{O} /$ acetone and $\mathrm{MeOH}$ to yield a library of resin-bound stannyl benzamides $(\mathbf{1 9 a} / \mathbf{b})$ using three $N, N$-dialkylpropyldiamines for resin 16a and one $N, N$-dialkylethyldiamine for resin $\mathbf{1 6} \mathbf{b}$, as shown in Table 3 .

MAS ${ }^{119} \mathrm{Sn}$ NMR spectra $\left(\mathrm{CHCl}_{3}\right)$ showed one peak in the range -39.8 to $-40.2 \mathrm{ppm}$.

DRIFT-IR spectra (solid, $\mathrm{cm}^{-1}$ ) showed $\mathrm{C}=\mathrm{O}$ absorptions in the range 1637 to 1640 and amide $\mathrm{N}-\mathrm{H}$ stretch, 3285-3307; 1537-1540 (amide N-H deformation).

Iodinolysis results presented in Table 3 are a combination of two separate analyses since $N$-succinimidyl-3-iodobenzoate does not survive the $\mathrm{pH} 5$ conditions.

Typical procedure for preparation of resin-supported 4-stannyl-benzamides by direct addition from Resin 1:

Poly-(4-\{dibutyl[2-(3-and 4-vinylphenyl)ethyl] stannyl\}- $N, N$-diethylpropylene diaminobenzamidyl)-co-divinylbenzene (19b-9)

A three-necked round-bottomed flask, equipped with a T-bore stopcock, a rubber septum, stir bar, and a powder addition side arm containing of resin 1 (175 mg, $1.67 \mathrm{mmol} / \mathrm{g}, 0.3 \mathrm{mmol})$ was evacuated and $\mathrm{N}_{2}$ introduced. Freshly distilled THF (40 mL) was added via syringe. The flask and its contents were cooled to $-78{ }^{\circ} \mathrm{C}$, evacuated and $\mathrm{N}_{2}$ introduced. Then $t$-BuLi $(770 \mu \mathrm{L}$, $1.2 \mathrm{mmol}$ ) was added dropwise to afford a $0.03 \mathrm{~mol} / \mathrm{L}$ solution. $N$-(3-(Diethylamino)propyl)-4bromobenzamide (184 mg, $0.59 \mathrm{mmol})$ in dry THF $(1 \mathrm{~mL})$ was added dropwise by syringe with vigorous stirring. After $2 \mathrm{~h}$ at $-78^{\circ} \mathrm{C}$, the resin was tipped into the solution and left to stir as the suspension warmed slowly to RT. After $\mathrm{MeOH}$ addition ( $3 \mathrm{~mL})$, the suspension was filtered and sequentially washed with $\mathrm{MeOH} /$ acetone, $\mathrm{MeOH} / \mathrm{H}_{2} \mathrm{O}, \mathrm{MeOH} /$ acetone $/ \mathrm{H}_{2} \mathrm{O}$, and $\mathrm{MeOH}$ several times to afford $\sim 180 \mathrm{mg}$ of resin 19b-9 after drying. ${ }^{119} \mathrm{Sn}$ MAS NMR spectrum (toluene): 82.0 
ppm (Sn-O) and -40.8 ppm (Sn-aryl). DRIFT-IR spectrum (solid, $\mathrm{cm}^{-1}$ ): 1637 (amide C=O) 3319 and 1538 (amide $\mathrm{N}-\mathrm{H})$. Iodinolysis: $0.37 \mathrm{mmol} \mathrm{N}$-(3-(diethylamino)propyl)-4iodobenzamide $\mathbf{2 0 b - 9}$ per gram of resin.

\section{Radiolabeling of [ $\left.{ }^{131} \mathrm{I}\right]-\mathrm{N}$-(2-morpholin-4-ylethyl)-4-iodobenzamide}

Radioiodination was carried out by adding $100 \mu \mathrm{L}$ of $0.1 \mathrm{~mol} / \mathrm{L} \mathrm{H}_{3} \mathrm{PO}_{4}, 70 \mu \mathrm{L}$ of n.c.a. $\mathrm{Na}^{131} \mathrm{I}(150 \mathrm{MBq}(4.05 \mathrm{mCi})$ in $0.1 \%$ aq. $\mathrm{NaOH})$ and $25 \mu \mathrm{L}$ of peracetic acid solution $(1 \mathrm{~mL}$ of glacial $\mathrm{AcOH}$ and $1.7 \mathrm{~mL}$ of $30 \%$ aq. $\mathrm{H}_{2} \mathrm{O}_{2}$ ) into a $2 \mathrm{~mL}$ vial containing a methanolic suspension of resin 19b-7 (3.2 mg in $100 \mu \mathrm{L})$. After $15 \mathrm{~min}$ at RT with stirring, $100 \mu \mathrm{L}$ of $0.2 \mathrm{~mol} / \mathrm{L}$ $\mathrm{Na}_{2} \mathrm{~S}_{2} \mathrm{O}_{3}$ was added to quench any excess iodine. The insoluble material was then passed through a Whatman $0.45 \mu \mathrm{m}$ nylon syringe filter. The filtrate containing the desired product was analyzed by radio-HPLC $\left(\mathrm{C}_{18}, 4.6\right.$ x $\left.250 \mathrm{~mm}\right)$ with $\mathrm{CH}_{3} \mathrm{CN} / \mathrm{Na}_{2} \mathrm{HPO}_{4}$ buffer $(5 \mathrm{mmol} / \mathrm{L}$, $\mathrm{pH} 7)$ as the mobile phase. Radiochemical yield (RCY) was defined as: [isolated radioactive ligand, $\mathrm{MBq}] /[$ total radioactivity added, $\mathrm{MBq}]$. 


\section{Supplementary data}

Available with the article: HPLC conditions, experimental procedures for iodobenzamide standards and SPE benzamide purification, resin SEM, MAS ${ }^{119}$ Sn NMR and DRIFT-IR spectra for resins, and HPLC chromatograms of SPE benzamide purification. Supplementary data are available with the article through the journal Web site at http://nrcresearchpress.com/doi/suppl/10.1139/cjc-2014-0265.

\section{Acknowledgements}

We wish to thank Progenics Pharmaceuticals, Inc., a subsidiary of Molecular Insight Pharmaceuticals, for ongoing financial, scientific, and morale support. This work was also supported by the Ontario Graduate Scholarship (OGS), the Natural Sciences and Engineering Research Council (NSERC) and the University of Western Ontario. Thanks to Chris Kirby and Doug Hairsine for their NMR and mass spectrometry assistance and to Mary Jane Walzak, Marina Suominen Fuller and Brad Kobe at Surface Science Western for their help with DRIFT spectroscopy and SEM analysis. 


\section{Figures and Tables}

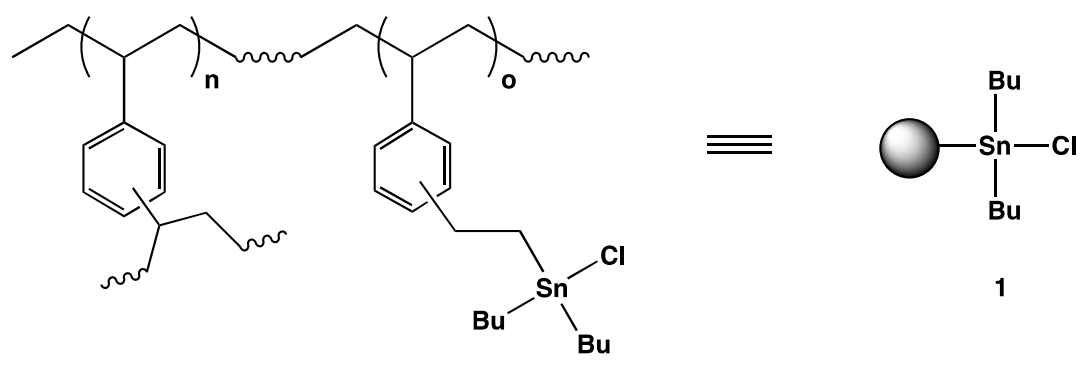

Fig. 1. Schematic of cross-linked polystyrene-based chlorostannane resin $\mathbf{1}$. 


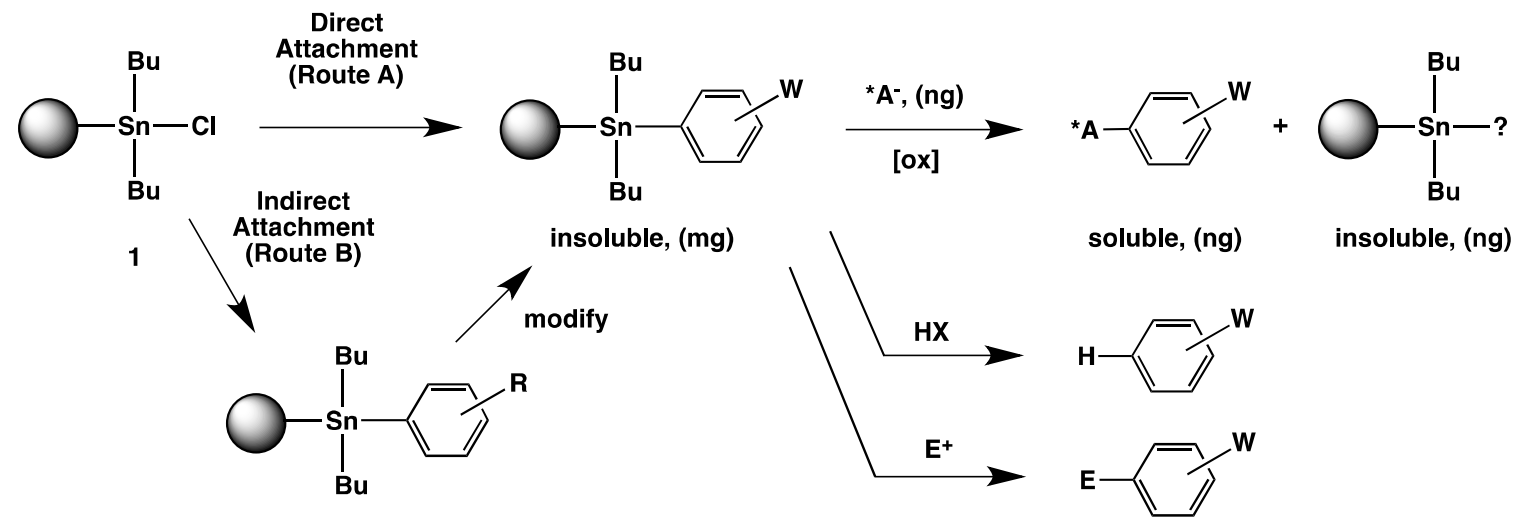

Fig. 2. Routes of preparation and release of benzene derivatives from stannyl resins.

$\mathbf{R}=$ Intermediate functionality, $\mathbf{W}=$ Target functionality, $* \mathbf{A}=$ Radionuclide, $\mathbf{H X}=$ Acid and $\mathbf{E}^{+}=$Electrophile 


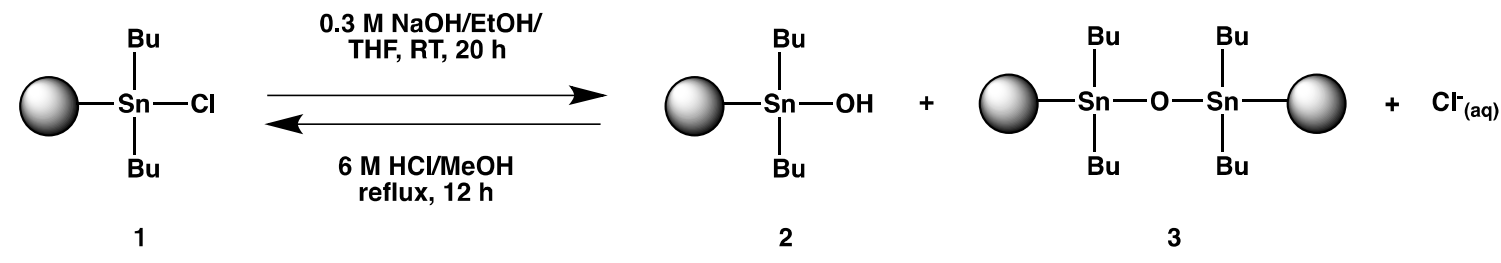

Fig. 3. Hydrolysis and regeneration of Resin 1 
Table 1. Incorporation of solvents into resins $\mathbf{1}$ and $\mathbf{2}$ determined by weight and volume increase.

\begin{tabular}{lllllllll}
\hline & $\mathrm{EtOH}$ & $\mathrm{H}_{2} \mathrm{O}$ & $\mathrm{EtOH} / \mathrm{H}_{2} \mathrm{O}^{a}$ & DMSO & $\mathrm{THF}$ & $\mathrm{CH}_{3} \mathrm{CN}$ & $\mathrm{C}_{6} \mathrm{H}_{6}$ & $\mathrm{C}_{7} \mathrm{H}_{8}$ \\
\hline Resin 1 & $1.5^{b} / 1.7^{c}$ & $0 / 0$ & $0.44^{b}$ & $2.6 / 3.2$ & $1.6 / 2.0$ & $1.0 / 1.5$ & $1.5 / 2.6$ & $0.9 / 1.2$ \\
Resin 4 & $1.4 / 3.0$ & $0.36 / 0.4$ & $1.9^{b}$ & $2.3 / 2.2$ & $1.2 / 2.8$ & $0.3 / 1.3$ & $0.5 / 1.5$ & 0 \\
\hline
\end{tabular}

${ }^{a} \mathrm{EtOH} / \mathrm{H}_{2} \mathrm{O} 1.25: 1$

${ }^{b}$ Weight ratios defined as: [(wt of resin + solvent $)-$ wt of resin]/wt of resin

${ }^{c}$ Volume ratio: [(volume of resin + solvent $)$ - volume of resin]/volume of resin 


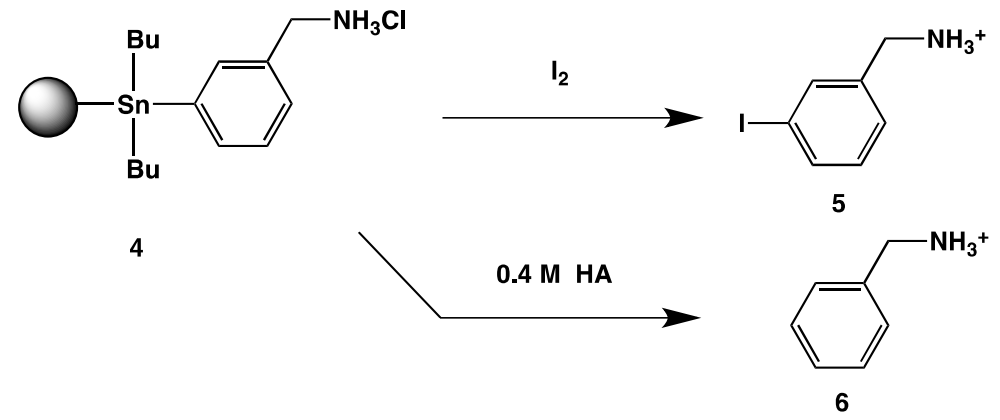

Fig. 4. Iodo- and protodestannylation of Resin 4. $\mathrm{A}=$ halide, $\mathrm{SO}_{4}{ }^{2-}, \mathrm{ClO}_{4}{ }^{-}, \mathrm{NO}_{3}{ }^{-}$ 


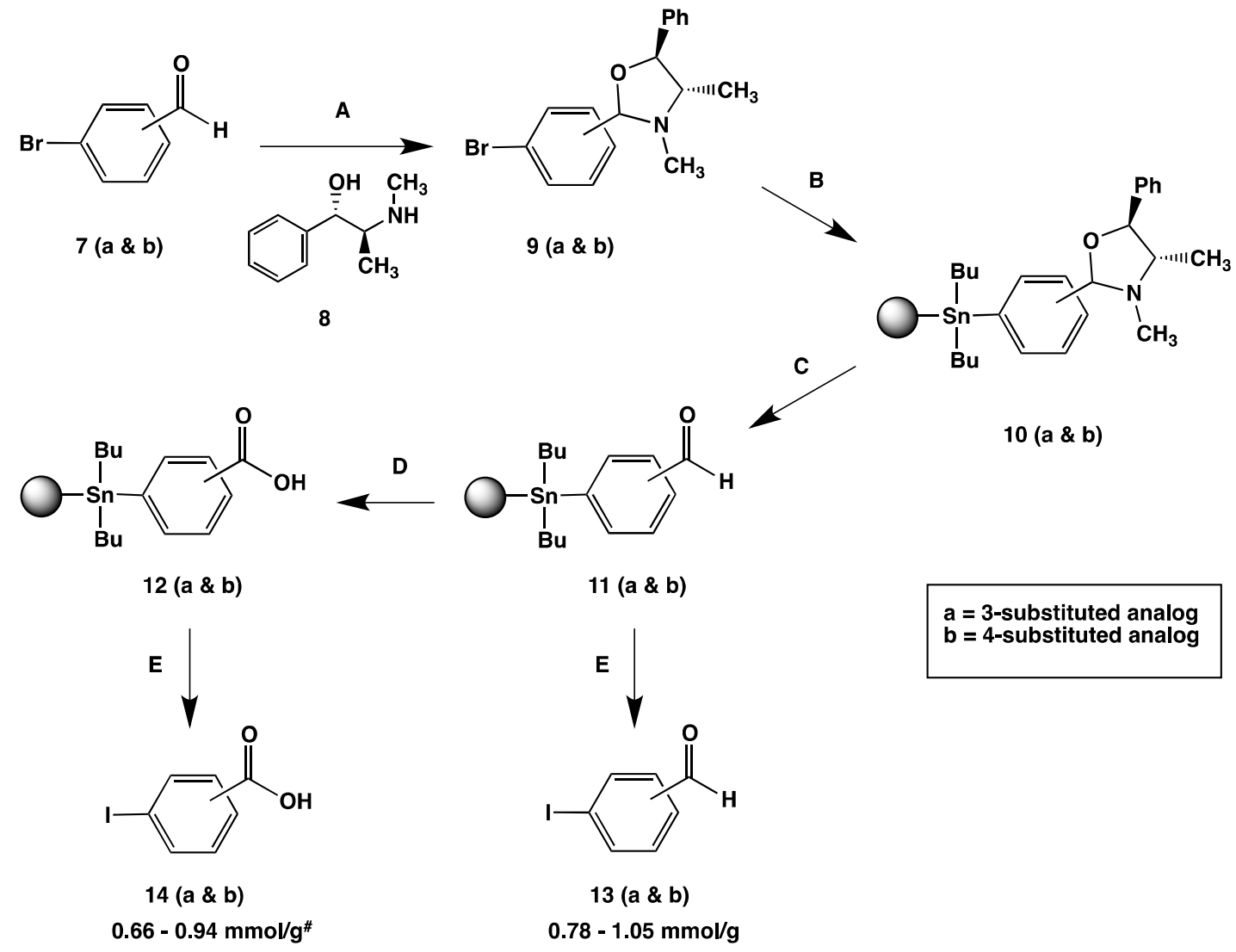

Fig. 5. Preparation of resin-supported benzoic acids (12a and 12b) from the corresponding bromobenzaldehydes ( (i) $n$ - $\mathrm{BuLi},-78^{\circ} \mathrm{C}$, THF (ii) Resin 1; (C) $\mathrm{AcOH} / \mathrm{H}_{2} \mathrm{O} / \mathrm{MeOH}$; (D) 3-Chloroperbenzoic acid; (E) $\mathrm{I}_{2} / \mathrm{CH}_{3} \mathrm{CN}$. 
A

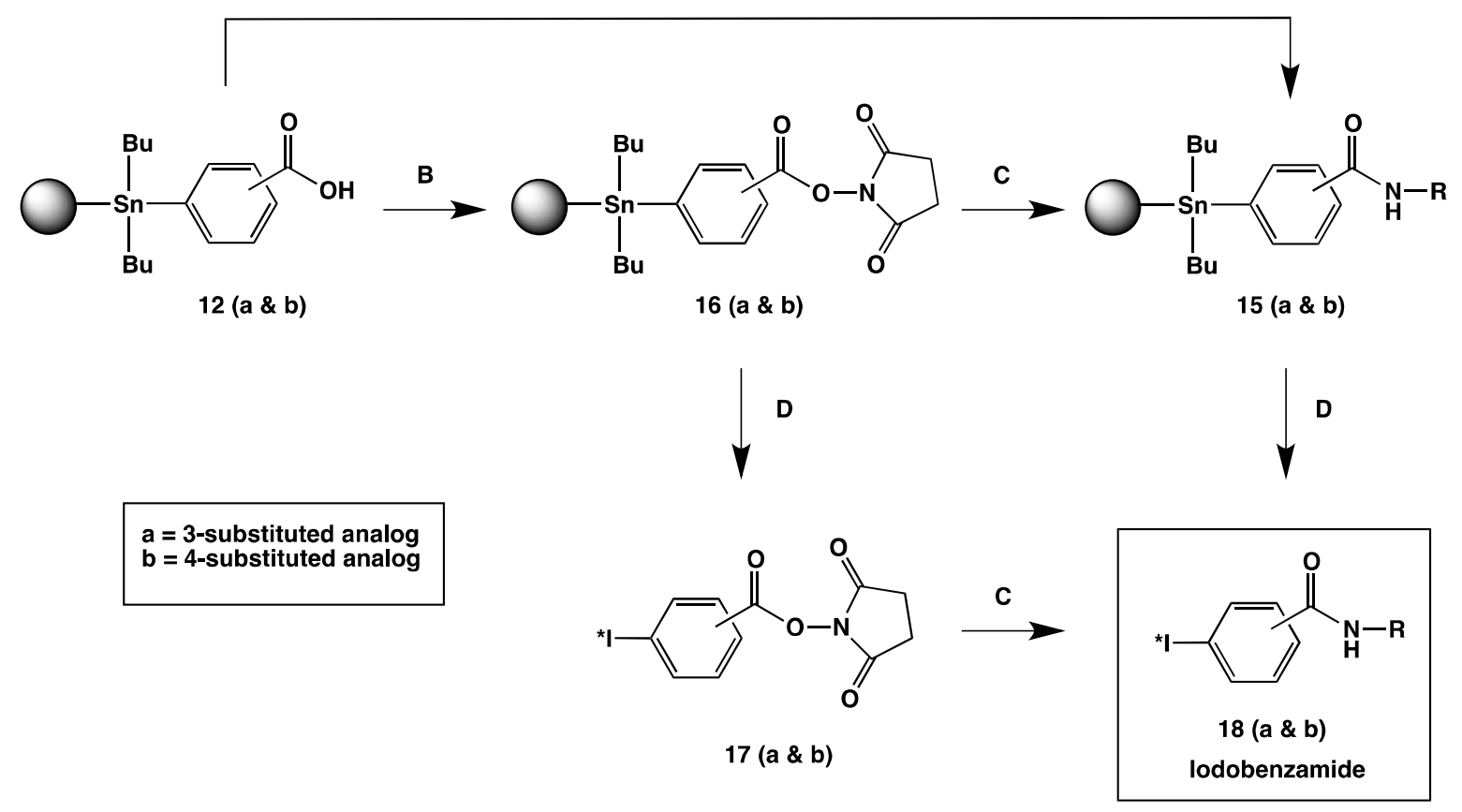

Fig. 6. Indirect approaches evaluated for synthesis of resin-supported benzamides.

Reagents: (A) Amines, DCC; (B) NHS, EDC; (C) Amines/amino acids/proteins; (D)* ${ }^{*}$, oxidant 

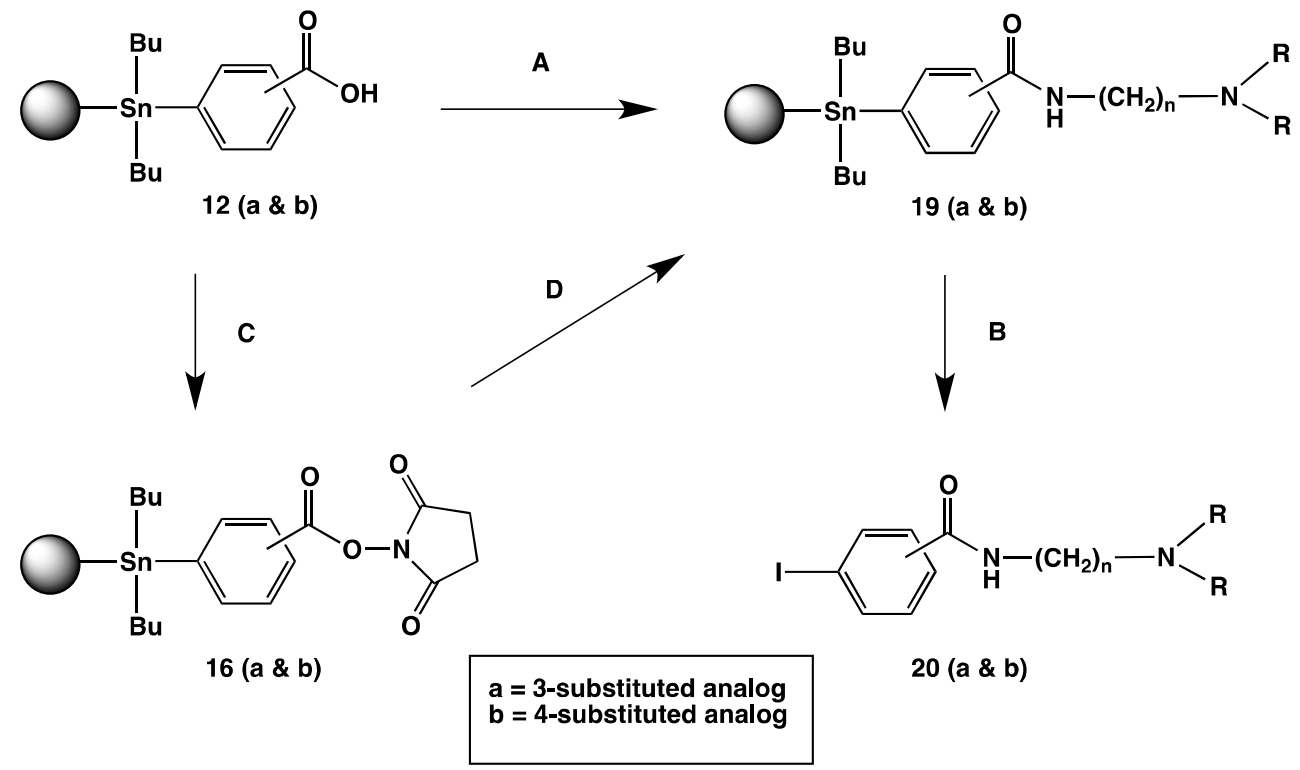

Fig. 7. Preparation of resin-bound benzamides 19a/b (both routes). Iodinolysis (condition B) results in a mixture of iodobenzamides, iodobenzoic acids and iodobenzaldehydes. See Table 2 for examples of mixture ratios. Reagents and conditions: (A) DCC, HOBT, DCM, diamine, 7 d; (B) $\mathrm{I}_{2}, \mathrm{CH}_{3} \mathrm{CN}$; (C) EDC, NHS, 24 h; (D) diamine, $24 \mathrm{~h}$. 
Table 2. Library of resin-bound 4-stannyl dialkylaminoethyl and propyl benzamides (19b-1 to 19b-12) prepared by amine/DCC/1-HOBT coupling with the resin-bound acid $\mathbf{1 2 b}$.

\begin{tabular}{|c|c|c|c|c|c|}
\hline \multirow{2}{*}{$\begin{array}{l}\text { Resin } \\
\text { 19b }\end{array}$} & \multirow{2}{*}{$n^{b}$} & \multirow[b]{2}{*}{$\mathrm{R}$} & \multicolumn{3}{|c|}{ Iodinolysis $(\mathrm{mmol} / \mathrm{g})^{a}$} \\
\hline & & & $\begin{array}{l}\text { 4-iodo- } \\
\text { benzamide }\end{array}$ & $\begin{array}{l}\text { 4-iodo-benzoic } \\
\text { acid }\end{array}$ & $\begin{array}{l}\text { 4-iodo- } \\
\text { benzaldehyde }\end{array}$ \\
\hline 1 & 2 & $\mathrm{CH}_{3}$ & 0.36 & 0.23 & 0.06 \\
\hline 2 & 2 & $\mathrm{CH}_{2} \mathrm{CH}_{3}$ & 0.40 & 0.10 & 0.05 \\
\hline 3 & 2 & $\mathrm{CH}\left(\mathrm{CH}_{3}\right)_{2}$ & 0.35 & 0.20 & 0.06 \\
\hline 4 & 2 & $\mathrm{CH}_{2} \mathrm{CH}_{2} \mathrm{CH}_{2} \mathrm{CH}_{3}$ & 0.39 & 0.14 & 0.06 \\
\hline 5 & 2 & $\left(\mathrm{CH}_{2}\right)_{4}$ & 0.32 & 0.29 & 0.05 \\
\hline 6 & 2 & $\left(\mathrm{CH}_{2}\right)_{5}$ & 0.41 & 0.17 & 0.05 \\
\hline 7 & 2 & $(\mathrm{CH} 2)_{2}(\mathrm{CH} 2)_{2} \mathrm{O}$ & 0.54 & 0.11 & 0.06 \\
\hline 8 & 3 & $\mathrm{CH}_{3}$ & 0.41 & 0.25 & 0.06 \\
\hline 9 & 3 & $\mathrm{CH}_{2} \mathrm{CH}_{3}$ & 0.29 & 0.27 & 0.10 \\
\hline 10 & 3 & $\mathrm{CH}_{2} \mathrm{CH}_{2} \mathrm{CH}_{2} \mathrm{CH}_{3}$ & 0.17 & 0.33 & 0.03 \\
\hline 11 & 3 & $\left(\mathrm{CH}_{2}\right)_{4}$ & 0.24 & 0.32 & 0.05 \\
\hline 12 & 3 & $(\mathrm{CH} 2)_{2}(\mathrm{CH} 2)_{2} \mathrm{O}$ & 0.40 & 0.18 & 0.04 \\
\hline
\end{tabular}

${ }^{a}$ HPLC conditions: $\mu$ Bondapak $\mathrm{C}_{18}$ column $(4.6 \times 250 \mathrm{~mm}) ; 60: 40 \mathrm{MeOH} / \mathrm{NaH}_{2} \mathrm{PO}_{4}$ buffer $[\mathrm{pH}$ 5]; $1 \mathrm{~mL} / \mathrm{min}$.

${ }^{b} n$ is the number of $\mathrm{CH}_{2}$ groups in the diamine moiety of the benzamides (see Fig. 7). 
Table 3. Iodinolysis results of resin-bound dialkyalaminoalkyl benzamides 19a and 19b prepared by coupling through $N$-succinimidyl ester bound resins $\mathbf{1 6 a}$ and $\mathbf{1 6 b}$, respectively.

\begin{tabular}{|c|c|c|c|c|c|}
\hline \multirow{2}{*}{$\begin{array}{l}\text { Resin } \\
\mathbf{1 9}\end{array}$} & \multirow{2}{*}{$n^{a}$} & \multirow{2}{*}{$\mathrm{R}$} & \multicolumn{3}{|c|}{ Iodinolysis $(\mathrm{mmol} / \mathrm{g})$} \\
\hline & & & $\begin{array}{l}\text { iodo- } \\
\text { benzamide }^{b}\end{array}$ & $\begin{array}{l}N \text {-succinimidyl- } \\
\text { iodobenzoate }^{c}\end{array}$ & $\begin{array}{l}\text { iodobenzoic } \\
\text { acid }^{b}\end{array}$ \\
\hline a-1 & 3 & $\mathrm{CH}_{2} \mathrm{CH}_{3}$ & 0.75 & 0.02 & 0.13 \\
\hline$a-2$ & 3 & $\mathrm{CH}_{2} \mathrm{CH}_{2} \mathrm{CH}_{2} \mathrm{CH}_{3}$ & 0.59 & 0.02 & 0.15 \\
\hline$a-3$ & 3 & $\left(\mathrm{CH}_{2}\right)_{4}$ & 0.64 & 0.01 & 0.17 \\
\hline b-2 & 2 & $\mathrm{CH}_{2} \mathrm{CH}_{3}$ & 0.43 & n.d. ${ }^{d}$ & 0.09 \\
\hline
\end{tabular}

${ }^{a} n$ is the number of $\mathrm{CH}_{2}$ groups in the diamine moiety of the benzamides (see Fig. 7).

${ }^{b} \mathrm{HPLC}$ conditions: $\mu$ Bondapak $\mathrm{C}_{18}$ column $(4.6$ x $250 \mathrm{~mm}) ; 60: 40 \mathrm{MeOH} / \mathrm{NaH}_{2} \mathrm{PO}_{4}$ buffer $[\mathrm{pH}$ 5]; $1 \mathrm{~mL} / \mathrm{min}$.

${ }^{c} \mathrm{HPLC}$ conditions: $\mu$ Bondapak $\mathrm{C}_{18}$ column $(4.6 \times 250 \mathrm{~mm}) ; 50: 50 \mathrm{CH}_{3} \mathrm{CN} / \mathrm{Na}_{2} \mathrm{HPO}_{4}$ buffer $[\mathrm{pH}$ 7]; $1 \mathrm{~mL} / \mathrm{min}$.

${ }^{d}$ n.d. $=$ not determined. 


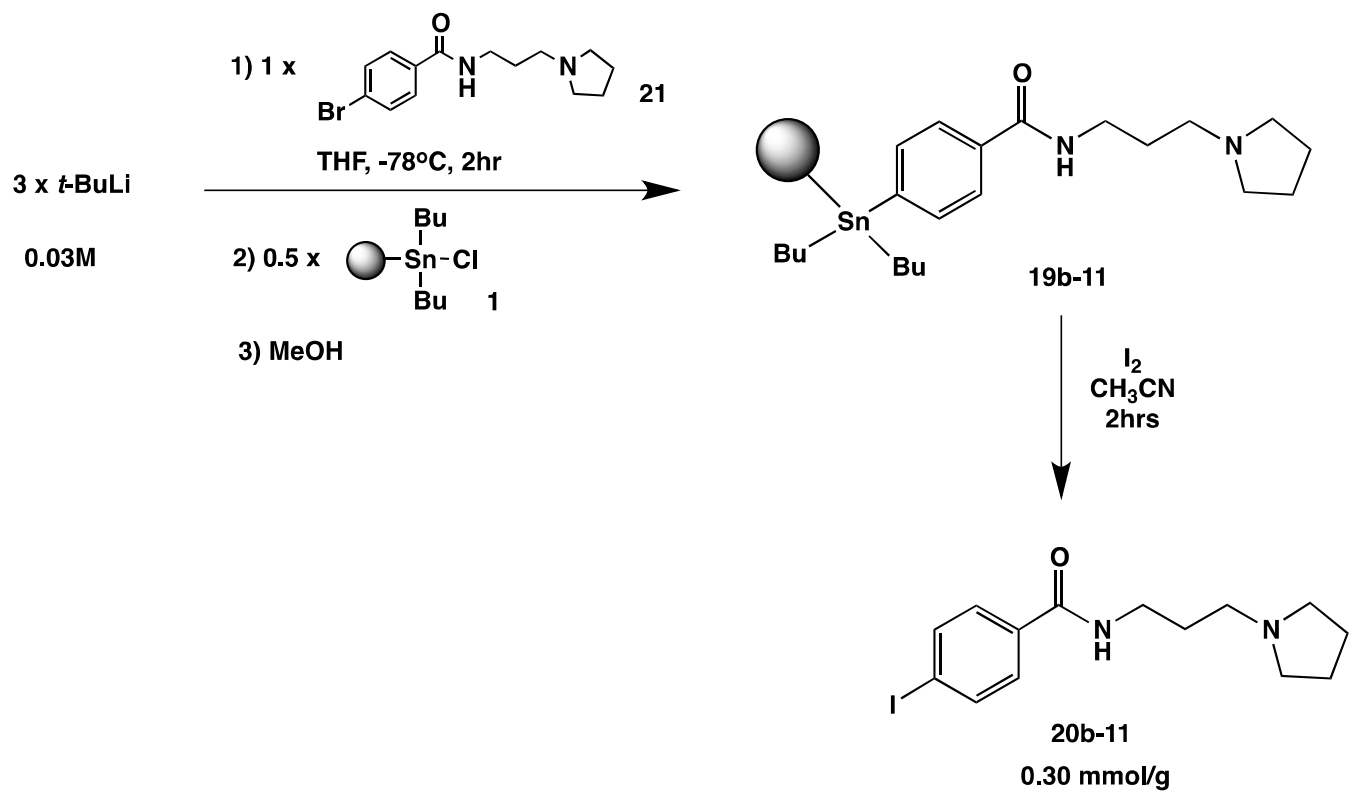

Fig. 8. Preparation of resin-bound benzamide $19 b-11$ by direct addition of dilithiated benzamide intermediate to resin 1. 

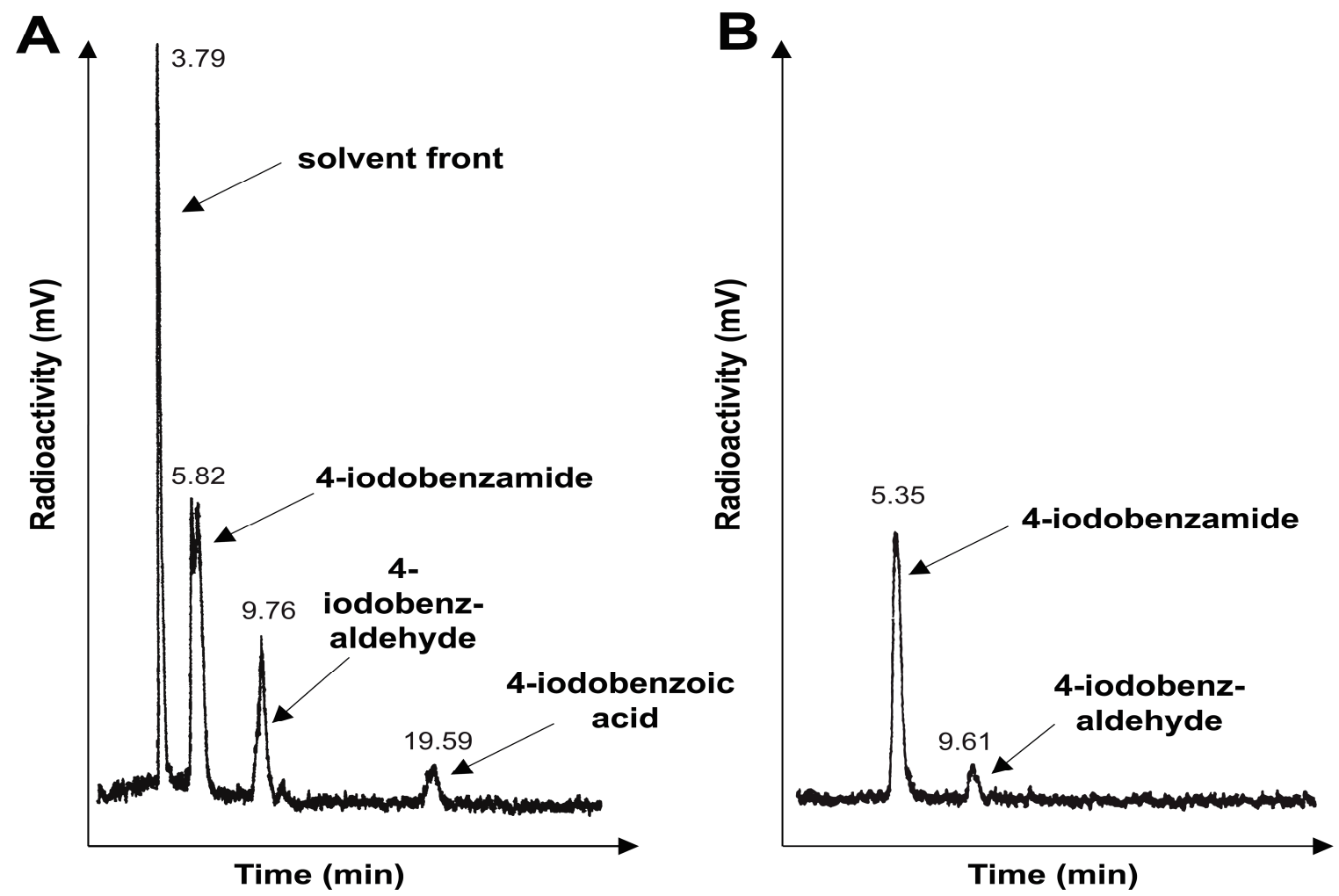

Fig. 9. RadioHPLC chromatograms following radioiodinlysis of resin-bound benzamide 19b-7 treated with $\mathrm{Na}^{131} \mathrm{I}_{\mathrm{H}} \mathrm{O}_{2} / \mathrm{AcOH}$ for $15 \mathrm{~min}$ at RT (A) after filtration and (B) after SPE purification. 


\section{References}

1. Culbert, P. A.; Hunter, D. H., React Polym 1993, 19 (3), 247. doi: http://dx.doi.org/10.1016/0923-1137(93)90082-Q.

2. Zhu, X.; Gobi, J.; Hunter, D. H., J. Nucl. Med. 1998, 39 (5), 143 P.

3. Hunter, D. H.; Zhu, X., J. Label. Compd. Radiopharm. 1999, 42 (7), 653. doi: 10.1002/(SICI)1099-1344(199907)42:7<653::AID-JLCR227>3.0.CO;2-Q.

4. Hunter, D. H.; Janabi, M.; Manning, B.; Zhu, X., J. Label. Compd. Radiopharm. 1999, 42 (S1), S793. doi: 10.1002/jlcr.25804401329.

5. Hunter, D. H.; Zhu, X. Preparation of radiolabelled haloaromatics via polymer-bound intermediates. USA Patent \#7,273,601 B2, issued September 25, 2007.

6. Hunter, D. H.; Janabi, M. Polymer precursors of radiolabeled compounds, and methods of making and using the same. US Patent \# 8,383,083 issued February 26, 2013.

7. Neumann, W. P., J. Organomet. Chem. 1992, 437 (1-2), $23 . \quad$ doi: http://dx.doi.org/10.1016/0022-328X(92)83429-L.

8. Hunter, D. H.; McRoberts, C., Organometallics 1999, 18 (26), 5577. doi: 10.1021/om990630d.

9. Davies, A. G. Organotin Chemistry. Wiley-VCH Verlag GmbH \& Co. KGaA: Federal Republic of Germany, 2004.

10. Smith, P. J. Chemistry of Tin. Blackie: London, 1998.

11. James, I. W., Tetrahedron 1999, 55 (16), 4855. doi: 10.1016/s0040-4020(99)00125-8.

12. Azedra is under commercial development by Progenics Pharmaceuticals.

13. Matthay, K. K.; Weiss, B.; Villablanca, J. G.; Maris, J. M.; Yanik, G. A.; Dubois, S. G.; Stubbs, J.; Groshen, S.; Tsao-Wei, D.; Hawkins, R.; Jackson, H.; Goodarzian, F.; Daldrup-Link, H.; Panigrahy, A.; Towbin, A.; Shimada, H.; Barrett, J.; Lafrance, N.; Babich, J., J. Nucl. Med. 2012, 53 (7), 1155. doi: 10.2967/jnumed.111.098624.

14. Yanik, G. A.; Parisi, M. T.; Shulkin, B. L.; Naranjo, A.; Kreissman, S. G.; London, W. B.; Villablanca, J. G.; Maris, J. M.; Park, J. R.; Cohn, S. L.; McGrady, P.; Matthay, K. K., J. Nucl. Med. 2013, 54 (4), 541. doi: 10.2967/jnumed.112.112334.

15. Vaidyanathan, G.; Affleck, D. J.; Alston, K. L.; Zhao, X. G.; Hens, M.; Hunter, D. H.; Babich, J.; Zalutsky, M. R., Bioorg. Med. Chem. 2007, 15 (10), 3430. doi: 10.1016/j.bmc.2007.03.016. 
16. Kabalka, G. W.; Namboodiri, V.; Akula, M. R., J. Label. Compd. Radiopharm. 2001, 44 (13), 921. doi: 10.1002/jlcr.518.

17. Goodman, M. M.; Kung, M. P.; Kabalka, G. W.; Kung, H. F.; Switzer, R., J. Med. Chem. 1994, 37 (10), 1535.

18. Elmaleh, D. R.; Fischman, A. J.; Shoup, T. M.; Byon, C.; Hanson, R. N.; Liang, A. Y.; Meltzer, P. C.; Madras, B. K., J. Nucl. Med. 1996, 37 (7), 1197.

19. Hanson, R. N.; Seitz, D. E.; Botarro, J. C., J. Nucl. Med. 1982, 23 (5), 431.

20. Morin, K. W.; Atrazheva, E. D.; Knaus, E. E.; Wiebe, L. I., J. Med. Chem. 1997, 40 (14), 2184. doi: 10.1021/jm9606406.

21. Kabalka, G. W.; Goodman, M. M.; Srivastiva, R. S.; Bowers, K. R.; Marks, R. C., J. Label. Compd. Radiopharm. 1994, 35 (S1), S220. doi: 10.1002/jlcr.25804401329.

22. Hunter, D. H.; Gagnon, K. J. Prosthetic groups attached to stannyl polymer in the synthesis of radiopharmaceuticals. US Patent \# 8,697,032, issued April 15, 2014.

23. Gifford, A. N.; Kuschel, S.; Shea, C.; Fowler, J. S., Bioconjug. Chem. 2011, 22 (3), 406.

24. Donovan, A.; Forbes, J.; Dorff, P.; Schaffer, P.; Babich, J.; Valliant, J. F., J. Am. Chem. Soc. 2006, 128 (11), 3536.

25. McIntee, J. W.; Sundararajan, C.; Donovan, A. C.; Kovacs, M. S.; Capretta, A.; Valliant, J. F., The Journal of organic chemistry 2008, 73 (21), 8236. doi: 10.1021/jo8013287.

26. Donovan, A. C.; Valliant, J. F., The Journal of organic chemistry 2009, 74 (21), 8133. doi: $10.1021 /$ jo901475d.

27. Dzandzi, J. P.; Vera, D. R.; Valliant, J. F., J Labelled Comp Radiopharm. 2014, 57 (9), 551.

28. Yong, L.; Yao, M. L.; Green, J. F.; Kelly, H.; Kabalka, G. W., Chemical communications 2010, 46 (15), 2623. doi: 10.1039/b925258d.

29. Yong, L.; Yao, M. L.; Kelly, H.; Green, J. F.; Kabalka, G. W., J. Label. Compd. Radiopharm. 2011, 54 (4), 173. doi: 10.1002/jlcr.1837.

30. Kabalka, G. W.; Yao, M. L.; Akula, M.; Yong, L., Pure Appl. Chem. 2012, 84 (11), 2309. doi: 10.1351/pac-con-12-01-13.

31. Marzinzik, A. L.; Felder, E. R., J. Org. Chem. 1998, 63 (3), 723.

32. Pham, T. Q.; Greguric, I.; Liu, X.; Berghofer, P.; Ballantyne, P.; Chapman, J.; Mattner, F.; Dikic, B.; Jackson, T.; Loc'h, C.; Katsifis, A., J. Med. Chem. 2007, 50 (15), 3561. doi: 10.1021/jm0701627. 
33. Zielinski, F. W.; Holly, F. E.; Robinson, G. D., Jr.; Bennett, L. R., Radiology 1977, 125 (3), 753.

34. John, C. S.; Bowen, W. D.; Saga, T.; Kinuya, S.; Vilner, B. J.; Baumgold, J.; Paik, C. H.; Reba, R. C.; Neumann, R. D.; Varma, V. M.; et al., J. Nucl. Med. 1993, 34 (12), 2169.

35. Brandau, W.; Niehoff, T.; Pulawski, P.; Jonas, M.; Dutschka, K.; Sciuk, J.; Coenen, H. H.; Schober, O., J. Nucl. Med. 1996, 37 (11), 1865.

36. Dittmann, H.; Coenen, H. H.; Zolzer, F.; Dutschka, K.; Brandau, W.; Streffer, C., Nucl. Med. Biol. 1999, 26 (1), 51.

37. Moins, N.; Papon, J.; Seguin, H.; Gardette, D.; Moreau, M. F.; Labarre, P.; Bayle, M.; Michelot, J.; Gramain, J. C.; Madelmont, J. C.; Veyre, A., Nucl. Med. Biol. 2001, 28 (7), 799.

38. Eisenhut, M.; Hull, W. E.; Mohammed, A.; Mier, W.; Lay, D.; Just, W.; Gorgas, K.; Lehmann, W. D.; Haberkorn, U., J. Med. Chem. 2000, 43 (21), 3913.

39. Bowen, W. D., Pharm. Acta Helv. 2000, 74 (2-3), 211. doi: http://dx.doi.org/10.1016/S0031-6865(99)00034-5.

40. Moins, N.; D'Incan, M.; Bonafous, J.; Bacin, F.; Labarre, P.; Moreau, M. F.; Mestas, D.; Noirault, E.; Chossat, F.; Berthommier, E.; Papon, J.; Bayle, M.; Souteyrand, P.; Madelmont, J. C.; Veyre, A., Eur. J. Nucl. Med. Mol. Imaging 2002, 29 (11), 1478. doi: 10.1007/s00259-0020971-6.

41. Zalutsky, M. R.; Narula, A. S., Cancer Res. 1988, 48 (6), 1446.

42. Frey, L. F.; Tillyer, R. D.; Caille, A. S.; Tschaen, D. M.; Dolling, U. H.; Grabowski, E. J. J.; Reider, P. J., J. Org. Chem. 1998, 63 (9), 3120. doi: 10.1021/jo971723c.

43. Neelakan, L., J. Org. Chem. 1971, 36 (16), 2256. doi: 10.1021/jo00815a012.

44. Michelot, J. M.; Moreau, M. F.; Veyre, A. J.; Bonafous, J. F.; Bacin, F. J.; Madelmont, J. C.; Bussiere, F.; Souteyrand, P. A.; Mauclaire, L. P.; Chossat, F. M.; et al., J. Nucl. Med. 1993, $34(8), 1260$.

45. Wilbur, D. S., Bioconjug. Chem. 1992, 3 (6), 433.

46. Vaidyanathan, G.; Zalutsky, M. R., Nat. Protoc. 2006, 1 (2), 707. doi: 10.1038/nprot.2006.99.

47. Beak, P.; Musick, T. J.; Chen, C. W., J. Am. Chem. Soc. 1988, 110 (11), 3538. doi: 10.1021/ja00219a031.

48. Beak, P.; Musick, T. J.; Liu, C.; Cooper, T.; Gallagher, D. J., J. Org. Chem. 1993, 58 (26), 7330. doi: 10.1021/jo00078a007. 
49. Gallagher, D. J.; Beak, P., J. Am. Chem. Soc. 1991, 113 (21), 7984. doi: 10.1021/ja00021a026.

50. Narasimhan, N. S.; Sunder, N. M.; Ammanamanchi, R.; Bonde, B. D., J. Am. Chem. Soc. 1990, 112 (11), 4431. doi: 10.1021/ja00167a047. 